NBER WORKING PAPER SERIES

\title{
SHAPING THE HABITS OF TEEN DRIVERS
}

Timothy J. Moore

Todd Morris

Working Paper 28707

http://www.nber.org/papers/w28707

\author{
NATIONAL BUREAU OF ECONOMIC RESEARCH \\ 1050 Massachusetts Avenue \\ Cambridge, MA 02138 \\ April 2021
}

We thank Dave Byrne, Tom Dee, Bill Evans, John de New, Greg Gilpin, Ben Hansen, Nathan Kettlewell, Julian Reif, Peter Siminski, Emma Shearer, Stefan Staubli and Jenny Williams for helpful comments, as well seminar/conference participants at the Australian Labour Econometrics Workshop, Bavarian Graduate Economics Workshop, College of the Holy Cross, Johannes Kepler University Linz, Max Planck Institute for Social Law and Social Policy, Purdue University, University of Connecticut, and University of Melbourne. We are grateful to the NSW Centre for Road Safety and Roads and Maritime Services NSW for data access and assistance, especially Phil Sparkes, Emma Shearer and Padma Uppuluri. The views expressed herein are those of the authors and do not necessarily reflect the views of the National Bureau of Economic Research.

NBER working papers are circulated for discussion and comment purposes. They have not been peerreviewed or been subject to the review by the NBER Board of Directors that accompanies official NBER publications.

(C) 2021 by Timothy J. Moore and Todd Morris. All rights reserved. Short sections of text, not to exceed two paragraphs, may be quoted without explicit permission provided that full credit, including @ notice, is given to the source. 
Shaping the Habits of Teen Drivers

Timothy J. Moore and Todd Morris

NBER Working Paper No. 28707

April 2021

JEL No. I18,K32

\section{ABSTRACT}

Teens are risky drivers and often subject to extra restrictions. We examine the effects of an Australian intervention banning first-year drivers from carrying multiple passengers between 11:00pm and 4:59am, which had represented 3\% of their accidents and $18 \%$ of their fatalities. Using daytime outcomes to account for counterfactual crash risks, we find the reform more than halves targeted crashes, casualties and deaths. The restriction also lowers crashes earlier in the evening and beyond the first year, suggesting it has broad and persistent effects on driving behavior. Overall, this targeted intervention delivers gains comparable to harsher restrictions that delay teen driving.

Timothy J. Moore

Department of Economics

Purdue University

403 W. State Street

West Lafayette, IN 47907

and NBER

moore839@purdue.edu

Todd Morris

Munich Center for the Economics of Aging

Max Planck Institute for

Social Law and Social Policy

Amalienstrasse 33, Munich 80799

Germany

toddstuartmorris@gmail.com 


\section{Introduction}

Driving is one of the riskiest activities that teens undertake. Studies report that $15-30 \%$ of teen drivers have an accident in their first year of driving (McCartt et al., 2009; Curry et al., 2015). Teens have a fatality risk per mile driven several times higher than adults (Tefft et al., 2013), and in most countries traffic accidents are teens' leading cause of death (Kyu et al., 2016).

Many governments have introduced restrictions on teen drivers in order to reduce these risks. These "graduated driver licensing" laws apply to learners and during an initial probationary period of unsupervised driving. Laws include minimum age requirements and licensing periods, passenger restrictions, nighttime curfews, and cellphone bans. Graduated licensing systems are used in Australia, Canada, New Zealand and the United States. Over 90\% of US teens are subject to both nighttime driving restrictions and passenger restrictions (Gilpin, 2019).

While studies find that some restrictions reduce accidents, three issues limit their effectiveness. First, reductions mainly come from fewer teens getting driver's licenses (Gilpin, 2019). Incapacitation delays driving experience and the benefits of driving independently, which may be substantial relative to the value of reducing teen crashes (Dee et al., 2005). Second, risky driving still accounts for a large fraction of teen deaths. Peer passengers and nighttime driving elevate crash risks, especially in combination: Tefft et al. (2013) estimate that US teen drivers' fatality rates per mile driven are over 50 times higher for late-night driving with multiple peers than daytime driving alone. Between 1996 and 2010, the US went from nine states with nighttime restrictions and none with passenger restrictions to nearly all states having both (Williams et al., 2016). Yet there has been only a modest decline in the fraction of teen traffic fatalities that result from multi-passenger crashes late at night (11:00pm-4:59am), from 16\% before 1996 to $13 \%$ after $2010 .^{1}$ Third, the restrictions have no impact on crashes after they end (Dee et al., 2005; Karaca-Mandic and Ridgeway, 2010; Gilpin, 2019). Thus, there is little support for the National Highway Traffic Safety Administration's (1998) claim that "by creating safer teen drivers today, we also are helping them become safer, more responsible young adult drivers tomorrow" (p. 16).

\footnotetext{
${ }^{1}$ Authors' calculations for ages 16-19 from Fatal Accident Reporting System 1975-2018 (https://www.nhtsa .gov/content/nhtsa-ftp/251 [Accessed 04/19/2021]). Passenger and night restrictions apply separately, except in Louisiana. Our period matches states' median curfew start and end times (https://www.ghsa.org/state -laws/issues/teen $\% 20$ and $\% 20$ novice $\% 20$ drivers [Accessed 04/19/2021]).
} 
In this paper, we show that a targeted driving restriction can overcome these issues, resulting in large improvements in road safety. In July 2007, the Australian state of New South Wales (NSW) banned first-year drivers from carrying two or more passengers under the age of 21 between 11:00pm and 4:59am. As in the US, accidents with multiple passengers between these hours are high risk: in our setting, they had accounted for $2.8 \%$ of police-reported crashes involving first-year drivers but $18.3 \%$ of fatalities.

We examine the impacts of the restriction using administrative data on drivers' licenses linked to detailed crash data. Using multi-passenger crash outcomes per licensed driver, we estimate a difference-in-differences Poisson model that compares changes in the restricted period $(11: 00 \mathrm{pm}-4: 59 \mathrm{am})$ to the daytime $(8: 00 \mathrm{am}-7: 59 \mathrm{pm})$ to control for other factors affecting crash risks. After showing the pre-treatment trends in daytime and nighttime crashes are similar, we estimate that the restriction reduced reported crashes by $57 \%$, casualties by $50 \%$, and hospitalizations and fatalities by $58 \%$. Crashes targeted by the restriction accounted for $4.3 \%$ of fatalities involving first-year drivers, compared to $18.3 \%$ before the restriction.

We consider contemporaneous spillovers to: (i) multi-passenger crashes by first-year drivers near the 11:00pm-4:59am period; (ii) crashes by first-year drivers with zero or one passenger, during and near 11:00pm-4:59am; and (iii) all crashes with teen passengers during and near 11:00pm-4:59am. We find that there is a reduction in first-year drivers' multi-passenger crashes between 8:00pm and 10:59pm, suggesting that the restriction reduced trips for activities spanning several hours (e.g., movies, parties). We find no effects for the other two spillovers, indicating that there were no large responses in terms of first-year drivers taking fewer passengers or teens taking more trips with older drivers (e.g., parents, in taxis).

We assess whether the restriction had effects beyond the first year of driving. We find statistically significant reductions in nighttime multi-passenger crashes in the second and third years. There are no discernible differences beyond the third year, but by that time the underlying crash rates are just one-fifth those of first-year drivers. There is no evidence that the restriction delays the development of driving skills.

The evening spillovers and persistent effects more than double the impact of the policy. In total, the direct and indirect effects per 100,000 drivers amount to 5.9 fewer deaths, 41 fewer hospitalizations, 98 fewer minor casualties and 164 fewer crashes with property damage. Govern- 
ment estimates of the value of a statistical life and crash costs imply that these improvements are worth approximately $\mathrm{A} \$ 412$ million (US\$320 million), or $\mathrm{A} \$ 738$ (US\$570) per first-year driver. Reduced harm to passengers and other drivers account for nearly all of the gains, indicating that the restriction substantially reduced teen-driving externalities.

We examine the effects of the restriction on licensing and driving. The restriction does not appear to affect licensing, as teens have similar licensing trends as older first-year drivers who are less affected by it. However, it does appear to affect high-risk driving. As a measure of driving prevalence, we use multi-vehicle crashes that are not caused by younger drivers. We assign crash responsibility using police judgments and a machine-learning approach based on pre-restriction data. This approach requires less onerous assumption than previous studies using crash interactions (Levitt and Porter, 2001; Karaca-Mandic and Ridgeway, 2010). ${ }^{2}$ Both the first-year and longer-term crash reductions can be explained by less driving, with the latter implying that the restriction targeted driving that is not highly valued by teens.

While the restriction likely imposes much lower welfare costs than broader interventions that substantially reduce teen licenses and driving, it generates large safety gains. The estimated reduction in traffic deaths per teen is $45-90 \%$ of the overall impacts of "good" graduated licensing systems found by Dee et al. (2005) and Gilpin (2019), which typically combine the effects of nighttime curfews, passenger restrictions, older licensing ages, and long permit periods (McCartt et al., 2010). The effects on traffic fatalities are also similar to the estimated gains from increasing the US minimum driving age by one year (Huh and Reif, 2020).

We make several contributions to the literature. Most directly, we enhance the understanding of teen driving restrictions around graduated licensing systems, which are often evaluated as a whole (e.g., Dee et al., 2005; Morrisey et al., 2006; Karaca-Mandic and Ridgeway, 2010). Our results contrast with US research on teen passenger limits and nighttime curfews, which finds no effects on safety after controlling for the number of licenses (Gilpin, 2019). ${ }^{3}$

We also advance the broader economic literature on traffic safety. ${ }^{4}$ First, as discussed

\footnotetext{
${ }^{2}$ They assume equal and independent mixing between driver types, which likely fails in our setting.

${ }^{3}$ For reviews of the broader literature, see Shope (2006), Williams (2017) and O'Neill (2020).

${ }^{4}$ Economics studies have examined drunk-driving laws (Evans, Neville and Graham, 1991; Ruhm, 1996; Carpenter, 2004; Hansen, 2015); minimum legal drinking ages (Dee and Evans, 2001; Carpenter and Dobkin, 2009; Lovenheim and Slemrod, 2010; Lindo, Siminski and Yerokhin, 2016); seatbelt regulations (Peltzman, 1975; Dee and Evans, 2001; Cohen and Einav, 2003; Carpenter and Stehr, 2008); child safety seats (Levitt, 2008; Jones and Ziebarth, 2016; Anderson and Sandholt, 2019); speed limits (Dee and Sela, 2003; Ashenfelter and Greenstone,
} 
above, we show a targeted driving intervention can have sizable impacts. Second, safer driving behavior in our setting persists for two years after treatment, much longer than has been found in the literature. For example, Bauernschuster and Rekers (2019) find that speed-monitoring campaigns do not reduce accidents once they end, Abouk and Adams (2013) find that ongoing texting bans decrease crashes for one or two months before returning to their original levels, and Banerjee et al. (2019) find that the effects of drunk-driving enforcement persist for three months after it ends. Third, we highlight the importance of external costs in high-risk teen driving, complementing previous research on externalities and driving (e.g., Levitt and Porter, 2001; Edlin and Karaca-Mandic, 2006; Anderson and Auffhammer, 2014; van Benthem, 2015).

Finally, we add to a relatively small number of studies that find persistent behavioral changes after treatment ends. ${ }^{5}$ Like most non-experimental settings, several mechanisms could explain our results (Volpp and Loewenstein, 2020). ${ }^{6}$ The new law may have sent a signal to teens and their parents about social norms (Benabou and Tirole, 2011). Acemoglu and Jackson (2017) argue that laws are most likely to change norms when they ban fewer behaviors and conflict less with prevailing norms. The restriction we study was targeted, banning a type of driving that accounts for only $0.5 \%$ of trips made by adults. ${ }^{7}$ Another potential mechanism is a change in tastes around driving activities. Severen and van Benthem (2021) document that gasoline price changes at ages 15-18 affect driving behavior decades later. They attribute this to formative driving experiences affecting long-term preferences. Similarly, Kueng and Yakovlev (2021) find that Russian anti-alcohol campaigns and beer-market expansion permanently changed the alcohol tastes of males who were affected at ages 14-18. A targeted ban when driving is first permitted may shape long-term driving preferences. Consistent with this, we find that the treatment effects are more persistent among teens always subject to the ban than teens who started driving independently before the restriction went into effect. Our findings suggest that policies that narrowly shape teens' driving behavior can markedly improve traffic safety.

2004); and police enforcement (DeAngelo and Hansen, 2014; Gallagher and Fisher, 2020).

${ }^{5}$ E.g., Charness and Gneezy (2009); Allcott and Rogers (2014); Bernedo et al. (2014); Halpern et al. (2015); Loewenstein et al. (2016); Schaner (2018).

${ }^{6}$ Direct learning is unlikely to be important, although the restriction may have increased learning about alternate transport options and activities (Larcom et al., 2017).

${ }^{7}$ Authors' calculations using 2009 US National Household Travel Survey (https://nhts.ornl.gov/downloads [Accessed 04/19/2021]). 


\section{Background}

New South Wales is Australia's most populous state, with approximately eight million residents. Driving laws are subject to primary enforcement, which is conducted by a single state police agency. In 2006, the year before the nighttime passenger restriction was introduced, NSW had 7.4 traffic fatalities per 100,000 residents. This is similar to the recent OECD average (7.0 per 100,000 in 2016). Like Canada, the UK and the US, NSW has seen a steady decrease in traffic fatalities since the 1970s (Figure A1).

The graduated driver licensing system in NSW has several stages. ${ }^{8}$ From age 16, individuals who pass a written test can get a learning permit. This allows the holder to drive with a fully licensed driver. From age 17, individuals can take computer and driving tests to get a probationary "P1" license. As discussed below, they must have held their learning permit for a minimum period and completed a minimum amount of supervised driving. The P1 license allows unsupervised driving, although drivers are prohibited from traveling faster than $90 \mathrm{kmh}$ (56 mph) on any road and must have zero blood alcohol concentration (BAC). ${ }^{9}$ Since July 2007, they are also subject to the nighttime passenger restriction described below. After holding a P1 license for one year, individuals can obtain a provisional "P2" license. ${ }^{10}$ The P2 license increases the speed restriction to $100 \mathrm{kmh}(63 \mathrm{mph})$ and removes the nighttime passenger restriction. Drivers can apply for an unrestricted license after holding a P2 license for two years, which removes the speed restriction and has a 0.05 BAC. ${ }^{11}$

Since July 2007, P1 drivers cannot carry more than one passenger aged under 21 years between 11:00pm and 4:59am. Drivers aged 25+ are exempt. Exemptions for employment, family or volunteering reasons can be sought in writing, but are rare. The restriction was announced in January 2007. Violations result in a fine - currently A $\$ 581$ (US\$445) — and three demerit points for drivers, one point away from suspension. Around $1 \%$ of first-year drivers were penalized for violations in the first year after implementation (Hildebrand and Kaye, 2008).

\footnotetext{
${ }^{8} \mathrm{NSW}$ licensing information is available at: https://www.rms.nsw.gov.au/roads/licence/index.html [Accessed 04/19/2021].

${ }^{9}$ Lindo et al. (2016) find NSW's legal drinking age of 18 has no effect on traffic accidents.

${ }^{10}$ During our sample period, graduation to P2 required passing a computer-based "Hazard Perception Test."

${ }^{11}$ With a minimum driving age of 17 , a multi-year licensing system, and vehicle signage requirements, NSW's system is very similar to New Jersey, other Australian states, and most Canadian provinces.
} 
Several other changes were introduced in July 2007. P1 drivers caught speeding had their licenses automatically suspended for three months. The minimum period for holding a learning permit increased from six to 12 months, while the minimum hours of supervised driving increased from 50 to 120. Learner, P1 and P2 drivers were also banned from using cellphones and required to display signs on their vehicle identifying their license stage. Siskind et al. (2019) and Kettlewell and Siminski (2020) examine the impact of the learner-permit restrictions on crash outcomes, with the former comparing two different cohorts of license holders and the latter using a birth-cohort regression discontinuity design. Neither find changes in crash outcomes, although Kettlewell and Siminski (2020) find that requiring 50 hours of supervised driving since 2000 reduced teen crashes. We compare nighttime to daytime outcomes to separate the effects of the nighttime passenger restriction from other factors affecting crashes.

\section{Data}

We use two administrative datasets from the NSW Department of Transport. The first is a census of NSW driving license records for everyone born since 1980, which allows us to follow drivers aged under 25 throughout our sample period. It includes sex, age, and the dates that different licenses were obtained. The second dataset, CrashLink, contains detailed information on crashes reported to NSW Police. Crashes are reported when there are fatalities, injuries, or vehicles towed. The dataset includes the month, year and exact time of the crash; each vehicle's passenger numbers; driver characteristics; and the number of fatalities and injuries. Age is not recorded for uninjured passengers and pedestrians. The datasets are linked at the driver level.

Using these data, we can identify drivers and crashes that were the target of the nighttime passenger restriction. We focus on the first 12 months of $\mathrm{P} 1$ driving, which is the minimum length of a P1 license. ${ }^{12}$ Our primary sample consists of drivers who obtained their P1 license before age 24, as the restriction does not apply from age 25. Most obtain their P1 license much earlier: in our sample, $58 \%$ got their license at age 17 and $84 \%$ by age 19 . We create a panel at the driver-year-month level for different times of the day from June 2004 to September 2014 , during which policies and reporting rules are consistent. ${ }^{13}$ We have 37 months before and

\footnotetext{
${ }^{12}$ Eligible P1 drivers visit the licensing agency to get their P2 license, which may be affected by the restriction. A sample of all P1 drivers is similar, as most P2 licenses are obtained within three months of eligibility.

${ }^{13}$ In May 2004, probationary drivers' BAC limit was reduced to zero. From October 2014, police no longer had to attend crashes with no casualties. A ban on P1 drivers using powerful vehicles was introduced in July 2005,
} 
87 months after the restriction was introduced. We have 239,158 drivers never subject to the restriction, 76,679 who had a P1 license when the restriction was introduced, and 558,207 always subject to it.

Crashes are reported at the monthly level. We include the month a driver obtains their P1 license and adjust for the number of days licensed in our analysis. Pre-restriction data provide background on the demographic and crash characteristics of first-year drivers (Table A1). On average, they are aged 18.8 years and $51.7 \%$ are male. First-year drivers involved in any crash are typically younger, less experienced and more likely to be male. These patterns are especially pronounced for the nighttime multi-passenger crashes that were the target of the restriction. Around two-thirds of these crashes occur on Friday and Saturday nights, and half involve multiple vehicles.

Before the reform, crashes declined strongly with experience (Figure A2). Quarterly crashes per 100,000 driver-years halve over the first year of driving, from 8,662 in the first quarter to 4,294 crashes in the fourth. After four years of driving, the crash rate is $69 \%$ lower than the initial rate. Nighttime multi-passenger crashes decline more sharply, dropping by $61 \%$ during the first year and $82 \%$ after four years. Inexperienced drivers have elevated crash risks, especially for nighttime multi-passenger crashes.

\section{The effects on multi-passenger crashes}

We estimate the impact of the nighttime passenger restriction by using daytime crashes to account for underlying changes in crash outcomes. Our key identifying assumption is that any underlying changes in crash risks or severity, such as changes in driving activity, traffic rules or vehicle safety, will have similar relative impacts on nighttime and daytime crash rates. Studies examining the impact of alcohol taxes and regulations on traffic safety have used a similar approach, as nighttime traffic fatalities are more likely to involve alcohol (e.g., Ruhm, 1996; Dee, 1999; Carpenter and Dobkin, 2011).

Figure 1a presents nighttime (11:00pm-4:59am) and daytime (8:00am-7:59pm) crash rates for first-year drivers carrying multiple passengers. Daytime rates are higher because most driving occurs during the day. However, in relative terms, the two series exhibit a similar, slightly

but it applies to few vehicles and had no apparent effects in our data. 
downward trend before the restriction. After its introduction, there is a sharp and persistent reduction in nighttime crashes and little change in the trend for daytime crashes. This suggests that daytime crashes can account for counterfactual trends in nighttime crashes and that the restriction reduced crashes. A regression-adjusted version with $95 \%$ confidence intervals shows no statistically significant differences across nighttime and daytime relative crash rates before the restriction and statistically significant reductions immediately after (Figure A3a). The figure shows no evidence of announcement-related anticipation effects.

The restriction may have had spillover effects on multi-passenger crashes at other times. Trips often span several hours; for example, US teen drivers who leave home in the evening are away for 2.3 hours on average. ${ }^{14}$ A reduction in such trips could decrease crashes in nearby hours, while shifting trips could increase crashes in nearby hours (e.g., not going to the movies versus attending an earlier screening). Given average trip lengths, we allow for spillover effects three hours either side of 11:00pm-4.59am, but also consider other ranges. ${ }^{15}$

We estimate the following difference-in-differences Poisson specification:

$$
y_{i y m p}=\exp \left\{\eta_{y m}+\theta_{p}+\mu_{m p}+\sum_{j=1}^{3} \beta_{j} \mathbf{1}\left(\operatorname{Period}_{p}=j\right) \times \operatorname{Post}_{y m}+X_{i y m p} \lambda\right\} \varepsilon_{i y m p}
$$

For a given outcome $y_{\text {iymp }}, i$ indexes individuals, $y$ years, $m$ months, and $p$ periods of the day. Four periods are used: restricted (11:00pm-4:59am), evening (8:00pm-10:59pm), morning (5:00am-7:59am), and daytime (8:00am-7:59pm). Indicator variables for the first three periods are interacted with Post $y m$, which identifies the post-restriction period. The key coefficients are $\beta_{j}$, which give the change in a crash outcome after the restriction was introduced relative to daytime outcomes. The percentage change in each outcome is given by $100 \times\left(\exp \left(\hat{\beta}_{j}\right)-1\right)$. We include year-month fixed effects $\eta_{y m}$ and period-of-day fixed effects $\theta_{p}$ to control for common crash determinants over time and across the day. Month-period fixed effects $\mu_{m p}$ are included to account for seasonal variation in crash outcomes across the day. The vector of individual controls $X_{i y m p}$ includes fixed effects for drivers' sex, months of age and months of experience,

\footnotetext{
${ }^{14}$ Authors' calculations from the 2009 US National Household Travel Survey (available at https://nhts . ornl .gov/downloads [Accessed 04/19/2021]). We use 16-19-year-olds who leave home 6:00pm-10:59pm and return home by 4:00am.

${ }^{15}$ Figures A3c and A3e show that multi-passenger crashes in these periods also have similar pre-restriction trends to daytime crash rates.
} 
which are interacted with the period-of-day dummy variables to allow for different impacts of driver composition across the day. We control for the number of days a license is held in the first, partial month of driving. The multiplicative error is $\varepsilon_{i y m p}$, and we allow for an arbitrary correlation in errors at the individual level. ${ }^{16}$

The results for multi-passenger crashes, casualties and hospitalizations or deaths are shown in columns 1-3 of Table 1. In addition to coefficients and standard errors, we show the implied changes as a percentage and per 100,000 driver-years. In the restricted period, crashes changed by $-57.1 \%$, casualties by $-50.1 \%$, and hospitalizations/deaths by $-57.6 \%$ (all $p<0.01$ ). In the evening period, crashes and casualties change $-15.3 \%$ and $-25.9 \%$ respectively (both $p<0.05$ ), while there is a statistically insignificant $-34.7 \%$ change in hospitalizations/deaths. There are no statistically significant effects in the morning period.

We assess the robustness of these results to how spillovers are measured. First, we divide the day into three-hour blocks and estimate a version of equation (1) with a reference period of 11:00am-1:59pm, which allows for policy effects nine hours before the restriction and six hours after. The estimates remain similar, with no evidence of further spillovers (Figure A4a). Second, spillover periods of two and four hours produce similar evening estimates and no discernible changes in morning crash outcomes (Table A2). These results are consistent with raw data on hourly crash rates before and after the reform, with large decreases in the restricted period and smaller decreases during 7:00pm-10:59pm (Figure A5).

The main estimates are also robust to using robust standard errors instead of clustering at the individual level; a negative binomial model; and Poisson and OLS models that use periodmonth-year counts rather than the license-panel structure (Table A3). The estimates are also similar when changing the sample to (a) first-year drivers who begin as teens or (b) all P1 drivers aged under 25 (Table A4). Finally, as a placebo exercise, we show there is no change in nighttime crashes only involving drivers aged 25+ (Table A5).

We examine which road users benefit from the restriction using a single 8:00pm-4:59am treatment period (Table A6). For the reduction in casualties, the point estimates imply that first-year drivers account for $24 \%$, their passengers $45 \%$, and other road users $31 \%$. For the reduction in hospitalizations/fatalities, first-year drivers account for $4 \%$, their passengers $46 \%$,

\footnotetext{
${ }^{16}$ We include fixed effects using the Poisson Pseudo-Maximum Likelihood estimator (Correia et al., 2020). We do not include individual fixed effects as age and experience are collinear at the individual level.
} 
and other road users 50\%. The restriction on first-year drivers generates substantial external benefits to other road users.

For every 100,000 first-year drivers, the direct effects and evening spillovers amount to reductions of 94 crashes, 98 casualties and 38 hospitalizations/fatalities. We separate the reductions in hospitalizations and fatalities using a single 8:00pm-4:59am treatment period and daytime outcomes from all crashes involving first-year drivers to increase precision. The estimates imply reductions per 100,000 drivers of 5.0 fatalities $(p<0.05)$ and 33.4 hospitalizations $(p<0.01){ }^{17}$ This estimated reduction in fatalities of $69 \%$ is similar to the $72 \%$ reduction in the raw data (from 7.5 to 2.1 per 100,000 driver-years). The large decline in serious outcomes limits concerns that crash-reporting changes can explain our results.

\section{The impact on other trips}

In response to the restriction, first-year drivers may have increased trips alone or with one passenger. To examine this possibility, we continue to use daytime outcomes as the comparison group. We first verify in Figure $1 b$ that the relative changes in daytime and nighttime crashes with zero or one passenger are similar prior to the restriction, and confirm this in a regressionadjusted version (Figure A3b). There is no visually apparent change in nighttime crashes after the restriction was introduced.

We estimate the spillover to crash outcomes involving zero or one passenger using equation (1). The results for crashes, casualties and hospitalizations/fatalities are shown in columns 4-6 of Table 1. The estimates are small and not statistically different from zero. The $95 \%$ confidence intervals imply that any increase in such crashes at 11:00pm-4:59am is at most $17 \%$ of the statistically significant decreases in multi-passenger crashes ( $15 \%$ for casualties). We confirm these estimates using similar robustness exercises to those for multi-passenger crashes (Figure A4b, Tables A3 and A4).

Another potential spillover is to trips where teens travel as passengers with an older driver, such as a parent. To examine this, we estimate the effects of the restriction on casualties at ages 16-20, excluding crashes that involve a P1 driver aged under 25. We use period-monthyear casualty counts and estimate a Poisson model using daytime outcomes as controls. The

\footnotetext{
${ }^{17}$ The sum of these effects matches the original point estimate (-38.4 versus -38.2 for hospitalizations/fatalities). This approach also produces similar casualty and crash estimates.
} 
estimated effects are small and not statistically significant (Table A7).

Trips with fewer passengers or older drivers have lower crash risks, making it difficult to assess substitution in terms of driving. Public transport trips, which we cannot observe, are even safer. However, any substitution is to lower-risk trips and not large enough to meaningfully change crash outcomes.

\section{Effects beyond the first year}

We examine the longer-term effects using a slightly modified sample and specification. We include crash outcomes for the first four years of driving and continue using daytime crash outcomes as the comparison group. We estimate the following Poisson specification:

$y_{i y m p}=\exp \left\{\nu_{y m}+\theta_{p}+\mu_{m p}+\operatorname{Post}_{i}+\sum_{d=1}^{4} \sum_{j=1}^{3} \beta_{d j} \mathbf{1}\left(\operatorname{Exp}_{\text {iym }}=d\right) \times \mathbf{1}\left(\operatorname{Period}_{p}=j\right) \times \operatorname{Post}_{i}+X_{\text {iymp }} \lambda\right\} \varepsilon_{\text {iymp }}$

where the index values and controls are the same as in equation (1). Indicator variables measuring each year of experience are interacted with the period-of-day indicator variables and Post ${ }_{i}$, which identifies drivers treated by the nighttime passenger restriction. This interaction produces our main coefficients of interest, $\beta_{d j}$, which measure the change in period-of-day $j$ relative to daytime outcomes for treated drivers in their $d^{\text {th }}$ year of driving relative to drivers of the same experience who were never subject to the restriction. ${ }^{18}$ We initially exclude partially treated drivers, but assess their response in the next section.

Figure 2 shows results for multi-passenger crash outcomes during 11:00pm-4:59am by years of experience. Figure 2a shows the implied percentage changes for crashes. The estimates are $-59 \%$ in the first year of driving, $-44 \%$ in the second, $-24 \%$ in the third, and $-15 \%$ in the fourth. The estimates for the first three years are statistically significant at the $5 \%$ level. The results for casualties in Figure 2b display a similar pattern, although the magnitudes decline more quickly and are only statistically significant in the first two years.

Figures $2 \mathrm{c}$ and $2 \mathrm{~d}$ show these impacts in absolute terms, by comparing the nighttime multipassenger crash and casualty rates of drivers subject to the restriction against the counterfactual

\footnotetext{
${ }^{18}$ We define the second year as the $14^{\text {th }}-24^{\text {th }}$ months of driving, as the $13^{\text {th }}$ month is partly in the first year for most drivers. We control for the effect in the $13^{\text {th }}$ month, but exclude it from our $\beta_{d j}$ estimates and adjust the implied effects in the second year to reflect a full year of driving. The third and fourth years include the $25^{\text {th }}-36^{\text {th }}$ and $37^{\text {th }}-48^{\text {th }}$ months, respectively.
} 
rates implied by our regression estimates. The reform flattened the crash-experience relationship for nighttime multi-passenger crashes. Without the reform, we estimate that crash rates in the fourth year would have been approximately one-fifth those in the first year. This matches how the pre-reform crash rates discussed in Section 3 decline with experience. After the reform, crash rates in the fourth year are only half those in the first year, yet still lower than the counterfactual. The restriction significantly improved outcomes until drivers gained experience and had much lower underlying crash risks.

We quantify the direct and evening-spillover effects in the $2^{\text {nd }}$ through $4^{\text {th }}$ years of driving (Table A8). Over the three years after the restriction, for every 100,000 first-year drivers there are changes of -57.2 crashes, -39.4 casualties and -6.1 hospitalizations/fatalities. ${ }^{19}$

\section{How did the restriction reduce crashes?}

We first consider changes in licensing, which do not seem to be an important determinant of our results. First, our estimates are not sensitive to conditioning on license numbers, as a Poisson model using aggregate crash counts produces similar estimates (Table A3). Second, the daytime crash rates in Figure 1b show no break in trend after the restriction is introduced, suggesting it did not change the composition of drivers. Third, licensing trends are similar across younger and older first-year drivers. While other licensing changes were introduced contemporaneously (see Section 2), only the nighttime passenger restriction was age-based. Teens' first-year licensing rates fall $8.5 \%$ in the 12 months after the restriction was introduced, which is similar to other annual changes during our sample period (Figure A6). Furthermore, this change is smaller than for new licensing among individuals aged 20-23, who are more likely to have passengers aged $21+$ not subject to the restriction. Attributing all licensing differences to the restriction results in per-population estimates that are $11 \%$ larger than our per-license estimates, although the available evidence suggests it is more appropriate to assume the per-population estimates are proportional to the per-license ones.

A related issue is whether the restriction reduced driving (fewer miles driven) or made driving safer (fewer crashes per mile driven). Previous studies have used the interaction of "treated" and "untreated" drivers in crashes to separate these factors in the context of drunk

\footnotetext{
${ }^{19}$ The longer-term effects on fatalities and hospitalizations are hard to estimate because the underlying rates are low. The point estimate for fatalities is -0.9 deaths per 100,000 drivers (see Appendix C).
} 
driving (Levitt and Porter, 2001) and graduated driving laws (Karaca-Mandic and Ridgeway, 2010). Our approach is to assume that the number of multi-vehicle crashes for which first-year drivers are not responsible is proportional to the amount they drive.

We use two measures of crash responsibility. The first are judgments by police, who mainly assign responsibility based on the vehicles' maneuvers before the crash (e.g., turning left, overtaking). Second, to address concerns that police may be more likely to blame first-year drivers for crashes after the restriction was introduced, we use machine-learning methods to predict the most responsible driver in each crash based on pre-restriction data (see Appendix B).

In Figure 3, we show the estimated changes and $95 \%$ confidence intervals for multi-vehicle crashes based on these measures. For first-year drivers, we estimate similar reductions in crashes where they were not responsible of $71 \%$ (police judgment) and $74 \%$ (predicted) to the $68 \%$ reduction for all multi-vehicle crashes. For the longer-term effects (years 2-4), the estimated reductions of $37 \%$ (police judgment) and $44 \%$ (predicted) are also similar to the $41 \%$ reduction for all multi-vehicle crashes. These results suggest that all of the crash reductions may be due to decreased driving, both in the first year and longer term.

To further understand the mechanisms, we assess the effects for partially treated drivers, who were already driving when the restriction was introduced (Table A9). Among these drivers, nighttime multi-passenger crashes decline by $40 \%$ under treatment in the first year of driving $(p<0.05)$. This estimate is approximately two thirds of the estimate for fully treated drivers, and the $p$-value on the hypothesis test of equal effect sizes is 0.077 . Over the $2^{\text {nd }}$ through $4^{\text {th }}$ years of driving, the crashes of partially treated drivers decline by a statistically insignificant $17 \%$. This is roughly one half of the estimate for fully treated drivers ( $p$-value for equality of coefficients: 0.069). Partially treated drivers have less persistent effects, which is consistent with the restriction affecting the initial development of driving habits or tastes.

Finally, we compare effect-heterogeneity in the first year and longer term. Previous studies of habit formation have found a positive correlation between short- and long-term effects for different subgroups (Fujiwara et al., 2016) and treatments (Charness and Gneezy, 2009; Ito et al., 2018). In our context, this would mean stronger long-term effects for drivers and driving behaviors that were more affected in the first year. For teen driving, a negative correlation is also possible, if the restrictions impede learning by doing (Dee et al., 2005; Karaca-Mandic 
and Ridgeway, 2010). Delayed skill development could mean that those more affected by the first-year restriction have higher subsequent crash risks.

Figure 4 presents the short- and long-term estimates for 13 types of crashes, with $95 \%$ confidence intervals in the appendix (Figure A7). The correlation is 0.94, suggesting that initial changes in behavior are the source of the persistent improvements. For example, the shortand long-term estimates are larger for female drivers, crashes on main roads, crashes involving multiple vehicles, crashes on Friday or Saturday nights, crashes in which the relevant driver was not speeding and crashes during 11:00pm-4:59am compared to 8:00pm-10:59pm. The lack of any negative correlation suggests that restricting nighttime driving with peers does not delay the development of driving skills, implying they can be gained through less risky types of driving.

These results suggest that the nighttime passenger restriction persistently changed teen driving behavior, but did not strongly influence licensing rates or the development of driving skills. Nighttime driving with multiple passengers appears discretionary and not highly valued by teens, even beyond their first year of driving. The results are consistent with the restriction changing norms or tastes around the type of driving targeted by the restriction.

\section{Conclusion}

The introduction of a nighttime passenger restriction for first-year drivers in NSW led to substantial safety improvements, which are large relative to other studies. We estimate that the restriction saves 5.0 lives per 100,000 drivers in the first year of driving. We imprecisely estimate that a further 0.9 lives per 100,000 drivers are saved in subsequent years. Approximately $85 \%$ of teens are treated by this restriction, so 5.0-5.9 lives per 100,000 teen drivers equates to $77-91 \%$ of the Dee et al. (2005) estimate for the lives saved by stringent US graduated licensing systems. Our estimate is $45-53 \%$ that of the Gilpin's (2019) estimate for more recent and stringent graduated licensing systems. As another comparison, our estimate is $73-102 \%$ of Huh and Reif's (2020) estimate for the mortality effects of increasing the minimum driving age by one year. ${ }^{20}$ Unlike in our setting, Gilpin (2019) finds that the gains from graduated licensing come from fewer licenses, while increasing the minimum driving age delays driving by definition.

Other crash outcomes are also important, especially as many teens experience major phys-

\footnotetext{
${ }^{20}$ Traffic fatalities account for $84 \%$ of their savings, with the rest coming from reducing non-traffic causes like drug overdoses. Our range considers both their overall and traffic-specific estimate.
} 
ical and mental trauma in crashes (Holbrook et al., 2005; Gardner et al., 2007). Our estimates indicate that, for every 100,000 first-year drivers, the restriction led to 41 fewer hospitalizations, 98 fewer other injuries, and 164 fewer crashes with property damage. We quantify the monetary value of these improvements (Appendix C). We use NSW Government valuations, which are consistent with international estimates for developed countries (Transport for NSW, 2019). The improvements over the first four years of driving are valued at $\mathrm{A} \$ 412 \mathrm{~m}$ (US\$320m), or $\mathrm{A} \$ 738$ (US\$570) per driver. It is not possible to accurately measure the welfare costs of the restriction, although the persistent effects suggest that many teens are willing to forgo nighttime driving with peers.

Policymakers often seek broad driving restrictions to improve teen safety, and calls for national standards often emphasize stricter limits on teen driving. For example, a 2011 US Congressional Act sought to prohibit drivers under 18 from driving at night or with more than one peer passenger. ${ }^{21}$ The substantial benefits found here suggest that targeted restrictions may shape safer driving behavior while allowing teens to develop driving skills and retain most of the benefits of independent driving. It may also bring about the behavioral changes that have been difficult to achieve in the early driving years and many other types of teen behavior.

\footnotetext{
${ }^{21}$ See https ://www . congress.gov/bill/112th-congress/senate-bill/528 [Accessed 04/19/2021].
} 


\section{References}

Abouk, Rahi, and Scott Adams. 2013. "Texting bans and fatal accidents on roadways: Do they work? Or do drivers just react to announcements of bans?" American Economic Journal: Applied Economics, 5(2): 179-99.

Acemoglu, Daron, and Matthew O Jackson. 2017. "Social norms and the enforcement of laws." Journal of the European Economic Association, 15(2): 245-295.

Allcott, Hunt, and Todd Rogers. 2014. "The short-run and long-run effects of behavioral interventions: Experimental evidence from energy conservation." American Economic Review, 104(10): 3003-37.

Anderson, D Mark, and Sina Sandholt. 2019. "Are booster seats more effective than child safety seats or seat belts at reducing traffic fatalities among children?" American Journal of Health Economics, 5(1): 42-64.

Anderson, Michael L, and Maximilian Auffhammer. 2014. "Pounds that kill: The external costs of vehicle weight." Review of Economic Studies, 81(2): 535-571.

Ashenfelter, Orley, and Michael Greenstone. 2004. "Using mandated speed limits to measure the value of a statistical life." Journal of Political Economy, 112(S1): S226-S267.

Australian Bureau of Statistics. 2020. "Wage Price Index, Australia, Catalogue Number 6345.0." https://bit.ly/2QisQzw.

Banerjee, Abhijit, Esther Duflo, Daniel Keniston, and Nina Singh. 2019. "The efficient deployment of police resources: Theory and new evidence from a randomized drunk driving crackdown in India." NBER Working Paper No. 26224.

Bauernschuster, Stefan, and Ramona Rekers. 2019. "Speed limit enforcement and road safety." IZA Working Paper No. 12863.

Benabou, Roland, and Jean Tirole. 2011. "Laws and norms." NBER Working Paper No. 17579.

Bernedo, Maria, Paul J Ferraro, and Michael Price. 2014. "The persistent impacts of norm-based messaging and their implications for water conservation." Journal of Consumer Policy, 37(3): 437-452.

Carpenter, Christopher. 2004. "How do zero tolerance drunk driving laws work?" Journal of Health Economics, 23(1): 61-83.

Carpenter, Christopher, and Carlos Dobkin. 2009. "The effect of alcohol consumption on mortality: Regression discontinuity evidence from the minimum drinking age." American Economic Journal: Applied Economics, 1(1): 164-82.

Carpenter, Christopher, and Carlos Dobkin. 2011. "The minimum legal drinking age and public health." Journal of Economic Perspectives, 25(2): 133-56.

Carpenter, Christopher S, and Mark Stehr. 2008. "The effects of mandatory seatbelt laws on seatbelt use, motor vehicle fatalities, and crash-related injuries among youths." Journal of Health Economics, 27(3): 642-662.

Charness, Gary, and Uri Gneezy. 2009. "Incentives to exercise." Econometrica, 77(3): 909931.

Cohen, Alma, and Liran Einav. 2003. "The effects of mandatory seat belt laws on driving behavior and traffic fatalities." Review of Economics and Statistics, 85(4): 828-843.

Correia, Sergio, Paulo Guimarães, and Tom Zylkin. 2020. "Fast Poisson estimation with high-dimensional fixed effects." The Stata Journal, 20(1): 95-115.

Curry, Allison E, Melissa R Pfeiffer, Dennis R Durbin, and Michael R Elliott. 2015. 
"Young driver crash rates by licensing age, driving experience, and license phase." Accident Analysis \& Prevention, 80: 243-250.

DeAngelo, Gregory, and Benjamin Hansen. 2014. "Life and death in the fast lane: Police enforcement and traffic fatalities." American Economic Journal: Economic Policy, 6(2): 231257.

Dee, Thomas S. 1999. "State alcohol policies, teen drinking and traffic fatalities." Journal of Public Economics, 72(2): 289-315.

Dee, Thomas S, and Rebecca J Sela. 2003. "The fatality effects of highway speed limits by gender and age." Economics Letters, 79(3): 401-408.

Dee, Thomas S, and William N Evans. 2001. "Behavioral policies and teen traffic safety." American Economic Review, 91(2): 91-96.

Dee, Thomas S, David C Grabowski, and Michael A Morrisey. 2005. "Graduated driver licensing and teen traffic fatalities." Journal of Health Economics, 24(3): 571-589.

Edlin, Aaron S, and Pinar Karaca-Mandic. 2006. "The accident externality from driving." Journal of Political Economy, 114(5): 931-955.

Evans, William N, Doreen Neville, and John D Graham. 1991. "General deterrence of drunk driving: Evaluation of recent American policies." Risk Analysis, 11(2): 279-289.

Fujiwara, Thomas, Kyle Meng, and Tom Vogl. 2016. "Habit formation in voting: Evidence from rainy elections." American Economic Journal: Applied Economics, 8(4): 160-88.

Gallagher, Justin, and Paul J Fisher. 2020. "Criminal deterrence when there are offsetting risks: Traffic cameras, vehicular accidents, and public safety." American Economic Journal: Economic Policy, 12(3): 202-37.

Gardner, Ricky, Gary A Smith, Anne-Marie L Chany, Soledad A Fernandez, and Lara B McKenzie. 2007. "Factors associated with hospital length of stay and hospital charges of motor vehicle crash-related hospitalizations among children in the United States." Archives of Pediatrics $\& 5$ Adolescent Medicine, 161(9): 889-895.

Gilpin, Gregory. 2019. "Teen driver licensure provisions, licensing, and vehicular fatalities." Journal of Health Economics, 66: 54-70.

Halpern, Scott D, Benjamin French, Dylan S Small, Kathryn Saulsgiver, Michael O Harhay, Janet Audrain-McGovern, George Loewenstein, Troyen A Brennan, David A Asch, and Kevin G Volpp. 2015. "Randomized trial of four financial-incentive programs for smoking cessation." New England Journal of Medicine, 372: 2108-2117.

Hansen, Benjamin. 2015. "Punishment and deterrence: Evidence from drunk driving." American Economic Review, 105(4): 1581-1617.

Hildebrand, Joe, and Byron Kaye. 2008. "Lifesaving P-plate laws: One year on and the rules are making a big impact." The Daily Telegraph, July 4, Sydney, Australia.

Holbrook, Troy L, David B Hoyt, Raul Coimbra, Bruce Potenza, Michael Sise, and John P Anderson. 2005. "Long-term posttraumatic stress disorder persists after major trauma in adolescents: New data on risk factors and functional outcome." Journal of Trauma and Acute Care Surgery, 58(4): 764-771.

Huh, Jason U, and Julian Reif. 2020. "Teenage driving, mortality, and risky behaviors." NBER Working Paper No. 27933.

Ito, Koichiro, Takanori Ida, and Makoto Tanaka. 2018. "Moral suasion and economic incentives: Field experimental evidence from energy demand." American Economic Journal: Economic Policy, 10(1): 240-67.

Jones, Lauren E, and Nicolas R Ziebarth. 2016. "Successful scientific replication and 
extension of Levitt (2008): Child seats are still no safer than seat belts." Journal of Applied Econometrics, 31(5): 920-928.

Karaca-Mandic, Pinar, and Greg Ridgeway. 2010. "Behavioral impact of graduated driver licensing on teenage driving risk and exposure." Journal of Health Economics, 29(1): 48-61.

Kettlewell, Nathan, and Peter Siminski. 2020. "Optimal model selection in RDD and related settings using placebo zones." IZA Discussion Paper No. 13639.

Kueng, Lorenz, and Evgeny Yakovlev. 2021. "The long-run effects of a public policy on alcohol tastes and mortality." American Economic Journal: Economic Policy, 13(1): 294-328.

Kyu, Hmwe H, Christine Pinho, Joseph A Wagner, Jonathan C Brown, Amelia Bertozzi-Villa, Fiona J Charlson, Luc Edgar Coffeng, Lalit Dandona, Holly E Erskine, Alize J Ferrari, et al. 2016. "Global and national burden of diseases and injuries among children and adolescents between 1990 and 2013: Findings from the global burden of disease 2013 study." JAMA Pediatrics, 170(3): 267-287.

Larcom, Shaun, Ferdinand Rauch, and Tim Willems. 2017. "The benefits of forced experimentation: Striking evidence from the London underground network." Quarterly Journal of Economics, 132(4): 2019-2055.

Levitt, Steven D. 2008. "Evidence that seat belts are as effective as child safety seats in preventing death for children aged two and up." Review of Economics and Statistics, 90(1): 158163.

Levitt, Steven D, and Jack Porter. 2001. "How dangerous are drinking drivers?" Journal of Political Economy, 109(6): 1198-1237.

Lindo, Jason M, Peter Siminski, and Oleg Yerokhin. 2016. "Breaking the link between legal access to alcohol and motor vehicle accidents: Evidence from New South Wales." Health economics, 25(7): 908-928.

Loewenstein, George, Joseph Price, and Kevin Volpp. 2016. "Habit formation in children: Evidence from incentives for healthy eating." Journal of Health Economics, 45: 47-54.

Lovenheim, Michael F, and Joel Slemrod. 2010. "The fatal toll of driving to drink: The effect of minimum legal drinking age evasion on traffic fatalities." Journal of Health Economics, 29(1): 62-77.

McCartt, Anne T, Daniel R Mayhew, Keli A Braitman, Susan A Ferguson, and Herbert M Simpson. 2009. "Effects of age and experience on young driver crashes: Review of recent literature." Traffic Injury Prevention, 10(3): 209-219.

McCartt, Anne T, Eric R Teoh, Michele Fields, Keli A Braitman, and Laurie A Hellinga. 2010. "Graduated licensing laws and fatal crashes of teenage drivers: A national study." Traffic Injury Prevention, 11(3): 240-248.

Morrisey, Michael A, David C Grabowski, Thomas S Dee, and Christine Campbell. 2006. "The strength of graduated drivers license programs and fatalities among teen drivers and passengers." Accident Analysis 83 Prevention, 38(1): 135-141.

National Highway Traffic Safety Administration. 1998. "Saving teenage lives: The case for graduated driver licensing." Washington DC: Department of Transportation.

O'Neill, Brian. 2020. "Driver education: How effective?" International Journal of Injury Control and Safety Promotion, 27(1): 61-68.

Peltzman, Sam. 1975. "The effects of automobile safety regulation." Journal of Political Economy, 677-725.

Ruhm, Christopher J. 1996. "Alcohol policies and highway vehicle fatalities." Journal of Health Economics, 15(4): 435-454. 
Schaner, Simone. 2018. "The persistent power of behavioral change: Long-run impacts of temporary savings subsidies for the poor." American Economic Journal: Applied Economics, 10(3): $67-100$.

Severen, Christopher, and Arthur van Benthem. 2021. "Formative experiences and the price of gasoline." mimeo.

Shope, Jean T. 2006. "Influences on youthful driving behavior and their potential for guiding interventions to reduce crashes." Injury Prevention, 12(suppl 1): i9-i14.

Siskind, Victor, Ian J Faulks, and Mary C Sheehan. 2019. "The impact of changes to the NSW graduated driver licensing system on subsequent crash and offense experience." Journal of Safety Research, 69: 109-114.

Tefft, Brian C, Allan F Williams, and Jurek G Grabowski. 2013. "Teen driver risk in relation to age and number of passengers, United States, 2007-2010." Traffic Injury Prevention, 14(3): 283-292.

Transport for NSW. 2019. "Transport for NSW economic parameter values." https://www.transport.nsw.gov.au/projects/project-delivery-requirements/evaluationand-assurance/resources (accessed 01/26/2021).

van Benthem, Arthur. 2015. "What is the optimal speed limit on freeways?" Journal of Public Economics, 124: 44-62.

Viscusi, W Kip. 2018. "Pricing lives: International guideposts for safety." Economic Record, 94: $1-10$.

Volpp, Kevin G, and George Loewenstein. 2020. "What is a habit? Diverse mechanisms that can produce sustained behavior change." Organizational Behavior and Human Decision Processes, 161: 36-38.

Williams, Allan F. 2017. "Graduated driver licensing (GDL) in the United States in 2016: A literature review and commentary." Journal of Safety Research, 63: 29-41.

Williams, Allan F, Anne T McCartt, and Laurel B Sims. 2016. "History and current status of state graduated driver licensing (GDL) laws in the United States." Journal of Safety Research, 56: 9-15. 
Figure 1: Crash rates of first-year drivers by the number of passengers and time of day

(a) Carrying two or more passengers

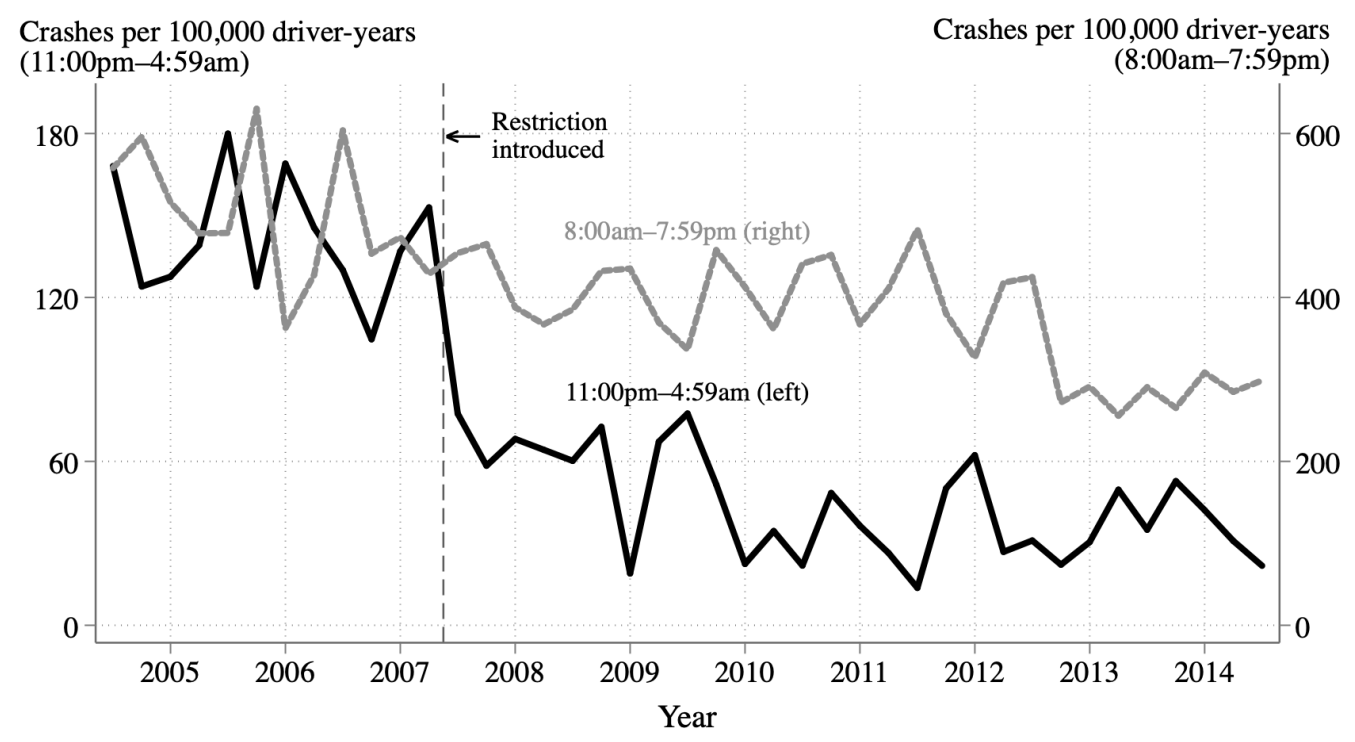

(b) Carrying zero or one passenger

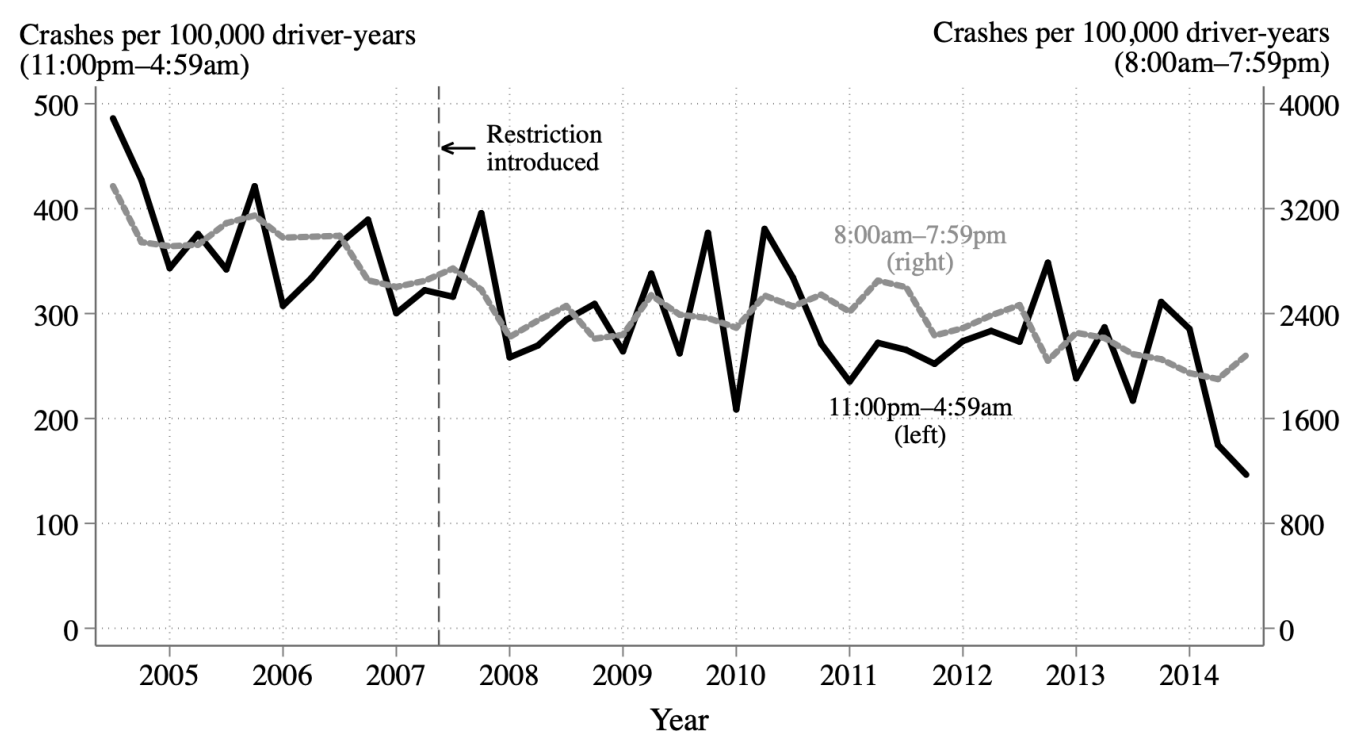

Notes: These figures show the quarterly crash rates of first-year drivers in NSW from July 2004 to September 2014. Panel (a) show that there are similar trends in multi-passenger crash rates across the nighttime (11:00pm-4:59am) and daytime $(8: 00 \mathrm{am}-7: 59 \mathrm{pm})$ periods until the restriction is introduced. Immediately after its introduction, there is a reduction in nighttime crash rates relative to daytime crash rates. Panel (b) shows that the trends in crash rates with zero or one passenger are similar across the nighttime and daytime periods both before and after the introduction of the nighttime passenger restriction. 
Figure 2: Immediate and subsequent impacts on nighttime multi-passenger crashes

(a) Percentage change in crash rates

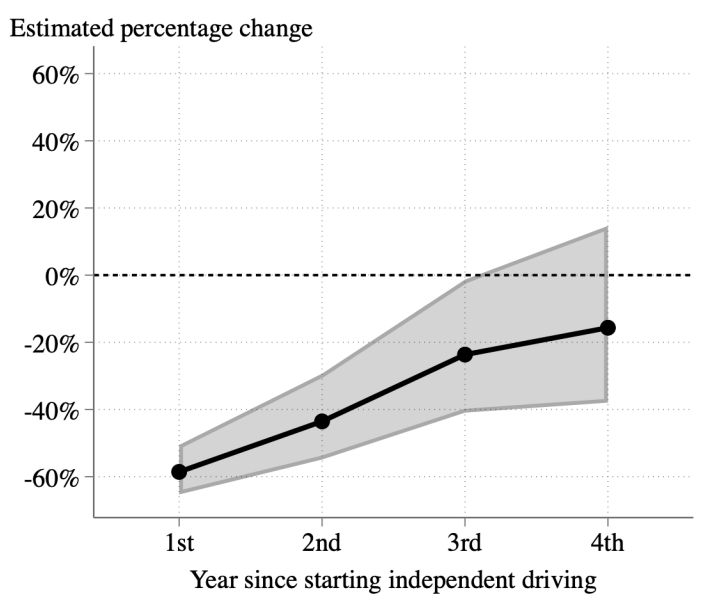

(c) Implied effect on crash rates

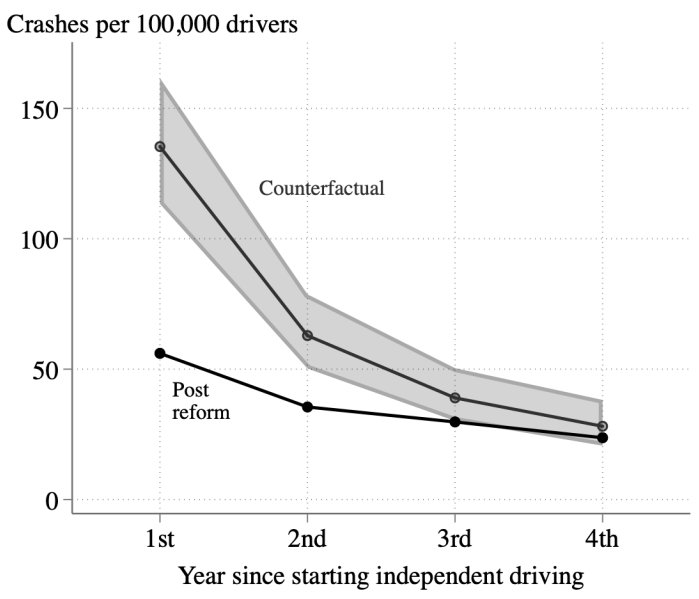

(b) Percentage change in casualties

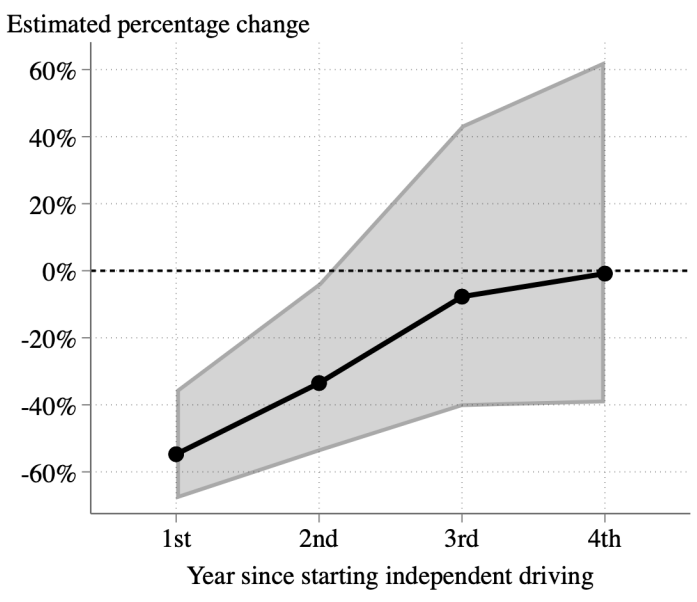

(d) Implied effect on casualties

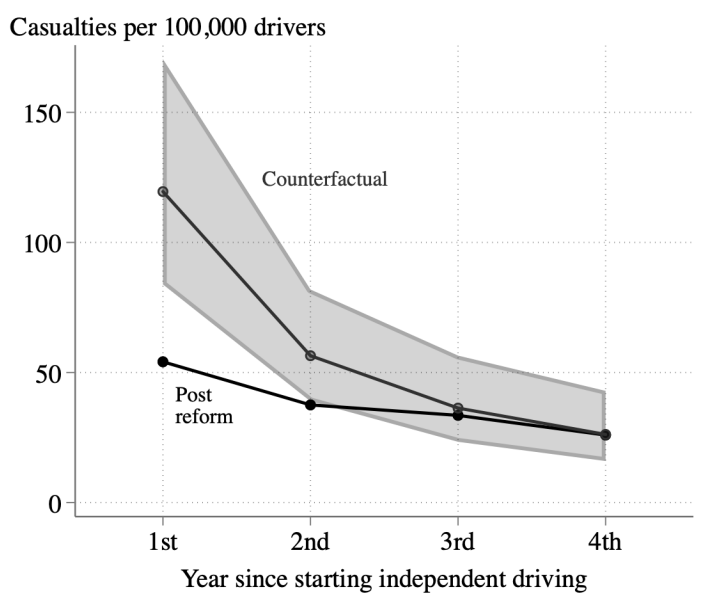

Notes: This figure shows the estimated effects and 95\% confidence intervals for nighttime (11:00pm-4:59am) multi-passenger crashes and casualties in the first year and the following three years when drivers are not subject to the restriction. The estimates come from equation (2) using driver-license and crash data from June 2004 to September 2014. In panels (a) and (b), the coefficients are translated into percentage changes, while in panels (c) and $(d)$ they are used to create counterfactual rates for drivers in the post-reform period. There are statistically significant reductions in crashes over the first three years and in casualties over the first two years, with a general pattern of the absolute effect size declining with years of driving. Table A8 presents the full estimates, including for the evening spillover and for serious casualties. 
Figure 3: Crashes where teen driver was not responsible as a measure of driving prevalence

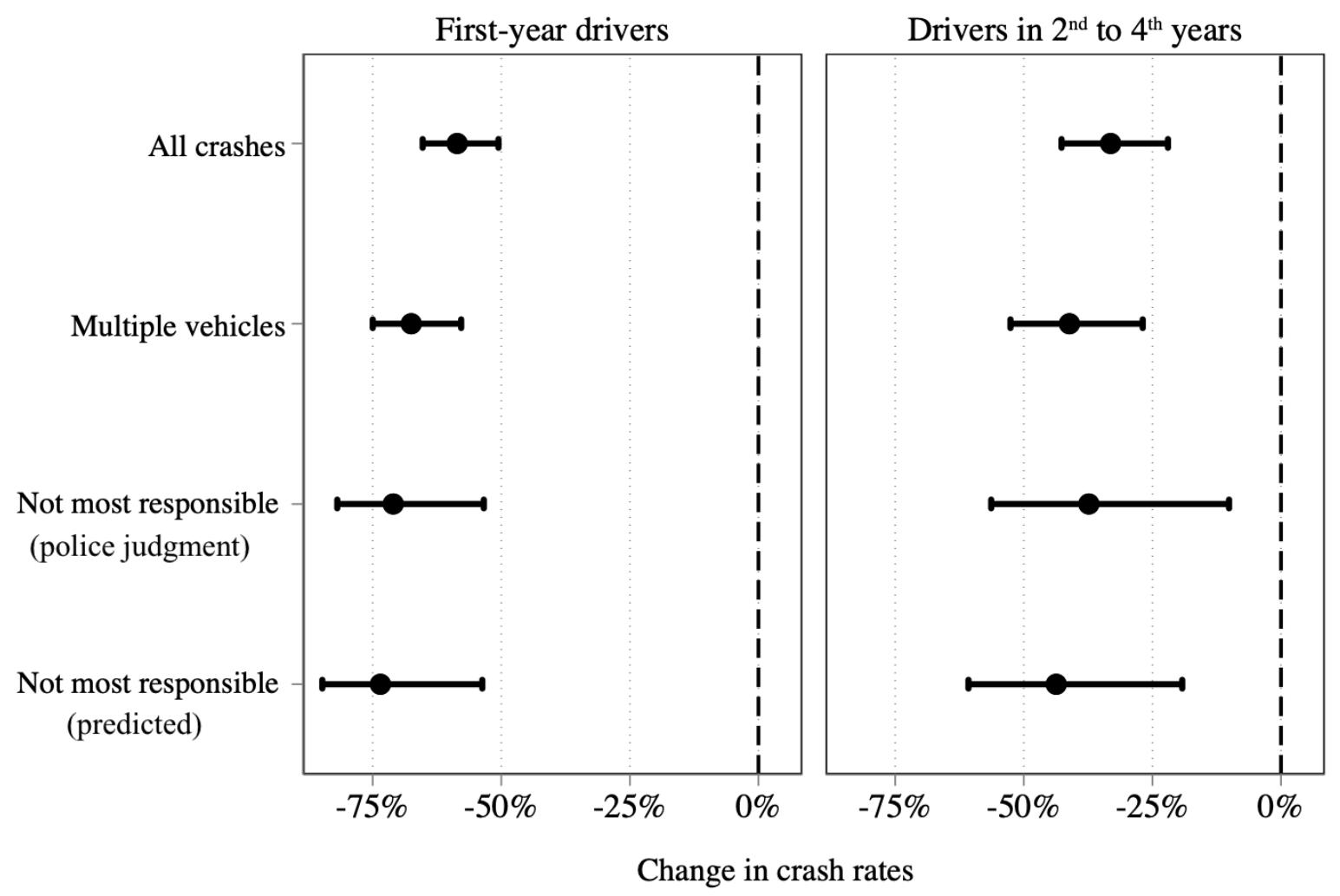

Notes: This figure shows the estimated percentage changes and 95\% confidence intervals for (i) all multi-passenger crashes in the restricted period (11:00pm-4:59am), (ii) the subset that involve multiple vehicles, and (iii) the subset that involve multiple vehicles where the teen driver was not responsible for the crash. The estimates are based on equation (2) for fully treated drivers. The longer-term estimates on the right are a weighted average of the effects in years 2-4 based on the crash rates in each year of driving (and standard errors calculated using the delta method). All estimates use driver-license and crash data from June 2004 to September 2014. Two measures of responsibility are used: (i) police reports and (ii) a machine-learning approach that assigns responsibility based on pre-reform crash data (see Appendix B for details). Both measures result in similar estimates. The figures show that the estimated reductions in nighttime multi-passenger crashes where first-year drivers/former firstyear drivers were not responsible are similar to the estimates for all such multi-passenger crashes. If crashes for which first-year drivers are not responsible measure the amount they drive (rather than crash risks), then these results suggest that both the first-year and longer-term results may be entirely due to reductions in the amount of nighttime multi-passenger driving. 
Figure 4: Correlation between first-year and longer-term treatment effect heterogeneity

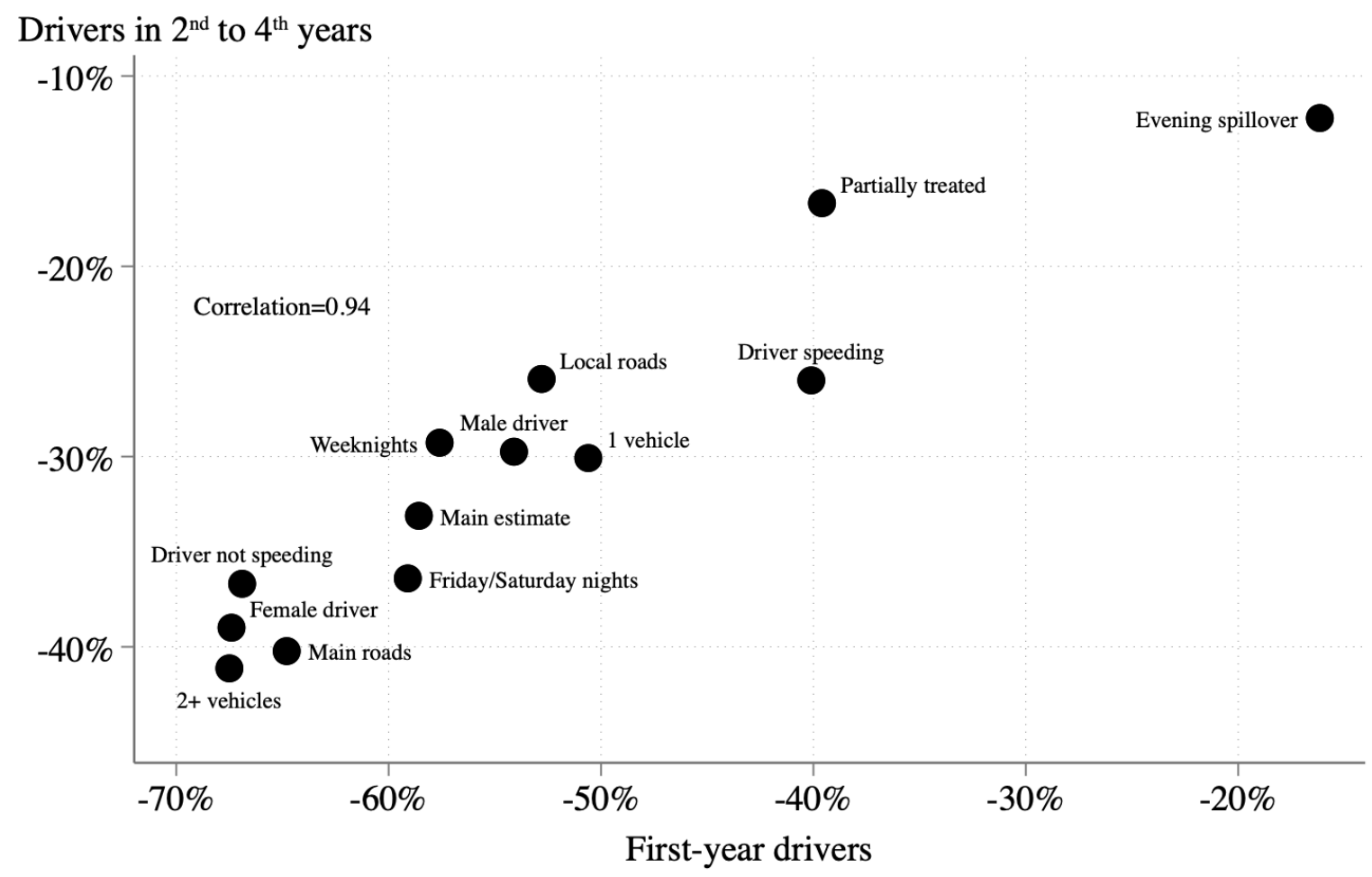

Notes: The figure shows the correlation between the treatment effect heterogeneity estimates in the first year and next three years of driving for multi-passenger crashes in the restricted period (11:00pm-4:59am). We also present the "evening spillover" effect on multi-passenger crashes in the 8:00pm-10:59pm period to facilitate comparisons to the overall effect in the restricted period ("main estimate"). The estimates are based on equation (2) with a sample of never treated and fully treated drivers (except for the partially treated estimate, which includes partially treated and excludes fully treated drivers). The longer-term estimates on the right are a weighted average of the effects in years 2-4 based on the crash rates in each year of driving. All estimates use driver-license and crash data from June 2004 to September 2014. The figure shows that there is a strong positive correlation between the size of the treatment effects in the first year, when the nighttime passenger restriction is in place, and the next three years of driving, when the restriction no longer applies. The $95 \%$ confidence intervals for all of these estimates are shown in Figure A7. 
Table 1: The effect of the nighttime passenger restriction on the crash outcomes of first-year drivers

\begin{tabular}{|c|c|c|c|c|c|c|}
\hline & \multicolumn{3}{|c|}{$\begin{array}{c}\text { Main estimates } \\
\text { (Carrying } 2+\text { passengers) }\end{array}$} & \multicolumn{3}{|c|}{$\begin{array}{l}\text { Estimates for } 0-1 \\
\text { passenger crashes }\end{array}$} \\
\hline & $\begin{array}{c}\text { All } \\
\text { crashes } \\
(1)\end{array}$ & $\begin{array}{c}\text { No. of } \\
\text { casualties } \\
(2)\end{array}$ & $\begin{array}{c}\text { No. in } \\
\text { hospital/ } \\
\text { killed } \\
(3)\end{array}$ & $\begin{array}{c}\text { All } \\
\text { crashes } \\
(4)\end{array}$ & $\begin{array}{c}\text { No. of } \\
\text { casualties } \\
(5)\end{array}$ & $\begin{array}{c}\text { No. in. } \\
\text { hospital/ } \\
\text { killed } \\
(6)\end{array}$ \\
\hline Direct effect: $11 \mathrm{pm}-4: 59 \mathrm{am}$ & $\begin{array}{l}-0.846 \\
(0.087)\end{array}$ & $\begin{array}{l}-0.696 \\
(0.167)\end{array}$ & $\begin{array}{l}-0.858 \\
(0.268)\end{array}$ & $\begin{array}{l}-0.036 \\
(0.042)\end{array}$ & $\begin{array}{l}-0.064 \\
(0.075)\end{array}$ & $\begin{array}{l}-0.240 \\
(0.137)\end{array}$ \\
\hline Implied percent change & $-57.1 \%$ & $-50.1 \%$ & $-57.6 \%$ & $-3.5 \%$ & $-6.2 \%$ & $-21.3 \%$ \\
\hline Change per 100,000 drivers & -68.1 & -57.6 & -24.8 & -11.8 & -10.7 & -12.7 \\
\hline Evening spillover: 8-10:59pm & $\begin{array}{l}-0.166 \\
(0.067)\end{array}$ & $\begin{array}{l}-0.300 \\
(0.121)\end{array}$ & $\begin{array}{l}-0.427 \\
(0.243)\end{array}$ & $\begin{array}{c}0.031 \\
(0.036)\end{array}$ & $\begin{array}{l}-0.001 \\
(0.063)\end{array}$ & $\begin{array}{l}-0.067 \\
(0.134)\end{array}$ \\
\hline Implied percent change & $-15.3 \%$ & $-25.9 \%$ & $-34.7 \%$ & $3.2 \%$ & $-0.1 \%$ & $-6.5 \%$ \\
\hline Change per 100,000 drivers & -25.4 & -40.7 & -13.4 & 15.6 & -0.2 & -4.3 \\
\hline Morning spillover: 5-7:59am & $\begin{array}{c}0.036 \\
(0.193)\end{array}$ & $\begin{array}{l}-0.073 \\
(0.351)\end{array}$ & $\begin{array}{l}-0.042 \\
(0.582)\end{array}$ & $\begin{array}{c}0.045 \\
(0.047)\end{array}$ & $\begin{array}{c}0.100 \\
(0.078)\end{array}$ & $\begin{array}{l}-0.076 \\
(0.169)\end{array}$ \\
\hline Implied percent change & $3.6 \%$ & $-7.1 \%$ & $-4.1 \%$ & $4.6 \%$ & $10.6 \%$ & $-7.3 \%$ \\
\hline Change per 100,000 drivers & 0.5 & -1.0 & -0.2 & 12.1 & 14.6 & -2.6 \\
\hline
\end{tabular}

Notes: This table presents the estimated changes in the crash outcomes of first-year drivers after the introduction of the restriction on carrying multiple passengers between 11:00pm and 4:59am. Estimates are based on equation (1), which is a Poisson difference-in-differences regression that uses daytime hours (8:00am-7:59pm) as the reference period and allows for spillover effects on nearby hours in the evening and morning. The sample comes from linked administrative driver-license and crash records from June 2004 to September 2014. Each regression uses 38,454,512 observations at the driver-month-year-period level. Standard errors in parentheses are clustered by driver. Columns (1)-(3) show the estimates for multi-passenger crashes, which were the target of the restriction. There are large and statistically significant reductions in all crash outcomes in the restricted period and in crashes and casualties in the adjacent evening period. Columns (4)-(6) show the estimates for crashes with zero or one passenger, and there is no evidence of spillovers to these crashes. See the text for more details. 


\title{
Web Appendix for "Shaping the Habits of Teen Drivers"
}

\author{
Timothy J. Moore Todd Morris
}

\section{Contents}

$\begin{array}{ll}\text { A Additional figures and tables } & \text { A1 }\end{array}$

B Predicting the most-responsible driver in multi-vehicle crashes $\quad$ B1

$\begin{array}{ll}\text { C Aggregating and valuing crash outcomes } & \text { C1 }\end{array}$

\section{List of Figures}

A1 Traffic fatality rates in New South Wales compared to Canada, the United Kingdom, the United States and the OECD average: $1970-2016 \ldots \ldots \ldots$. . . . . . . . A1

A2 The pre-restriction relationship between experience and crash rates in NSW $\quad \ldots \ldots$. . A2

A3 Changes in crash rates of first-year drivers relative to the six months before the introduction of the nighttime passenger restriction, by number of passengers and time of day . . . . . A3

A4 Estimated change in crash rates of first-year drivers in three-hour windows . . . . . . . A4

A5 Average crash rates of first-year drivers by hour before and after the reform by number of

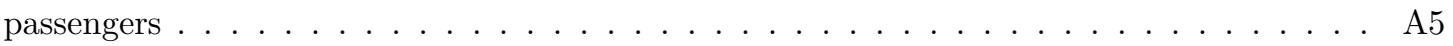

A6 Trends in the annual rate of new first-year $(\mathrm{P} 1)$ licenses by age $\ldots \ldots \ldots \ldots$. . . . A6

A7 The relationship between first-year and longer-term treatment effect heterogeneity $\ldots$. . A7

B1 Histogram of predicted probabilities for the younger driver being most responsible for multi-vehicle crashes before the restriction was introduced . . . . . . . . . B2

B2 Share of multi-passenger crashes 11:00pm-4:59am caused by the younger driver . . . . . B4

\section{List of Tables}

A1 Pre-reform license and crash characteristics of first-year drivers $\ldots \ldots \ldots \ldots$. . . . A8

A2 Effect of varying spillover periods for multi-passenger crash outcomes . . . . . . . . . . A9

A3 Robustness of main estimates to choice of regression model _ . . . . . . . . . . . A10

A4 Robustness of main estimates to different samples . . . . . . . . . . . . . . A11

A5 Placebo estimates for drivers aged $25+$, who are not subject to the nighttime multipassenger restriction . . . . . . . . . . . . . . . . . A A12

A6 The impact of the nighttime passenger restriction on different road users . . . . . . . . A13

A7 Impact of the restriction on teen casualties as non-peer passengers and pedestrians . . . . A14

A8 Effect on nighttime multi-passenger crashes and casualties by year of driving . . . . . . A15

A9 The impact of the restriction on crashes for fully versus partially treated drivers $\ldots \ldots$ A16 


\section{A Additional figures and tables}

Figure A1: Traffic fatality rates in New South Wales compared to Canada, the United Kingdom, the United States and the OECD average: 1970-2016

Fatalities per 100,000 people

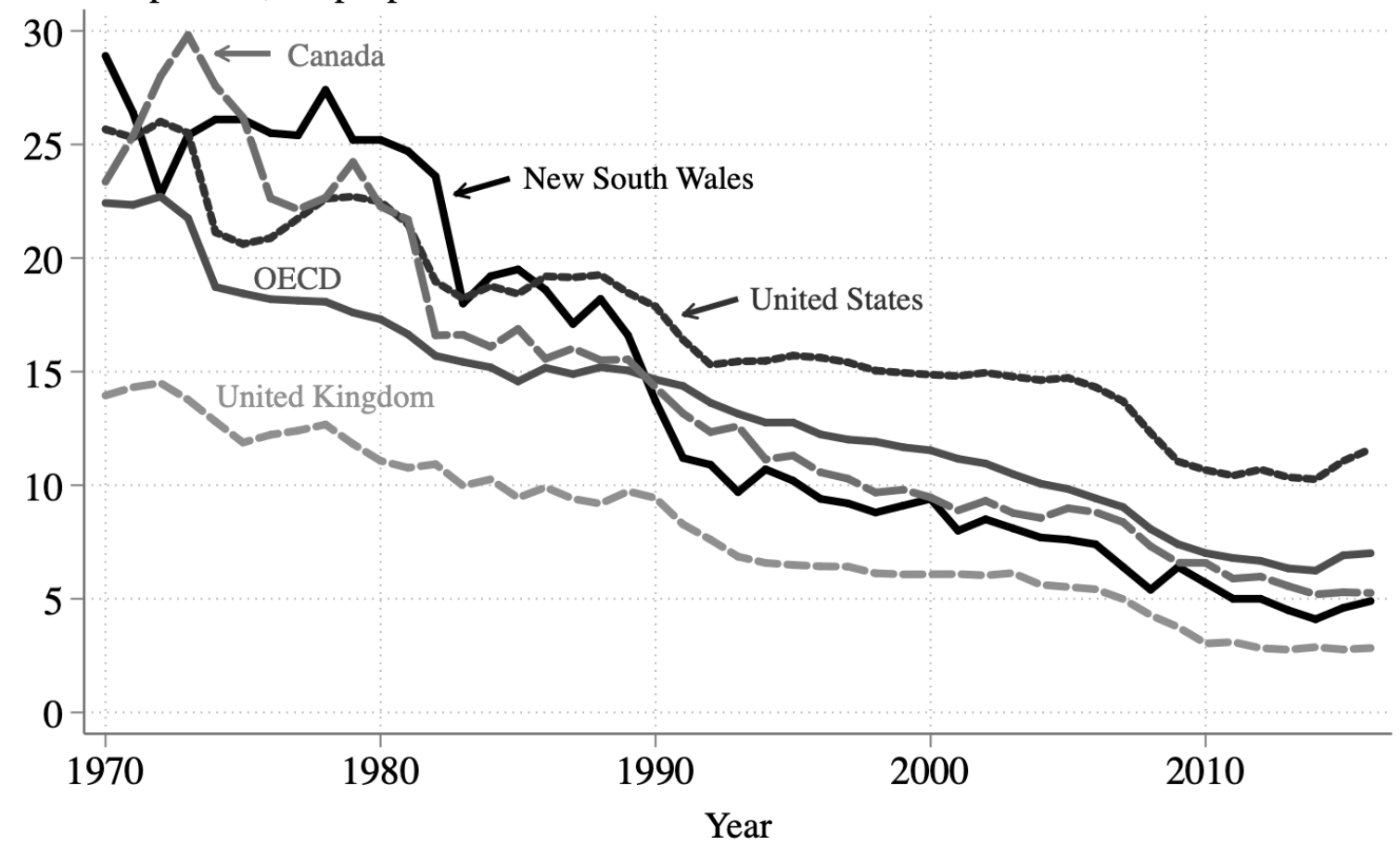

Notes: This figure shows the trends in traffic fatality rates in New South Wales and countries with similar traffic and legal systems. Sources: New South Wales Centre for Road Safety (https://roadsafety.transport .nsw.gov.au/statistics/index.html [Accessed 04/19/2021]) and authors' calculations using the Organization for Economic Cooperation and Development (OECD) Road Accident and Population databases (https://data . oecd.org/ [Accessed 04/19/2021]). OECD data excludes suicides involving the use of motor vehicles. The solid gray OECD line includes the 25 countries that were members of the OECD by 1973. 
Figure A2: The pre-restriction relationship between experience and crash rates in NSW

$$
\text { (a) All crashes }
$$

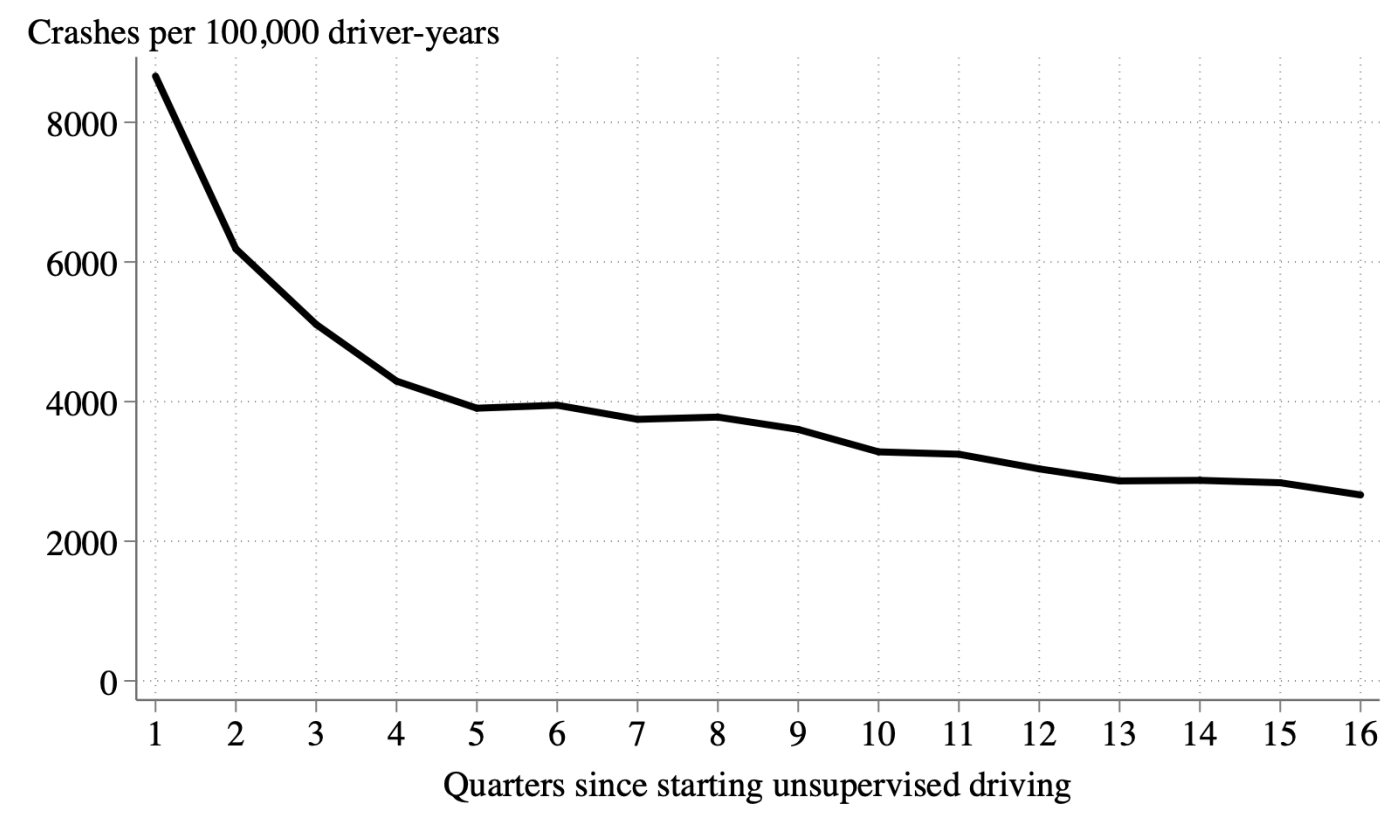

(b) Crashes with 2+ passengers, 11:00pm-4:59am

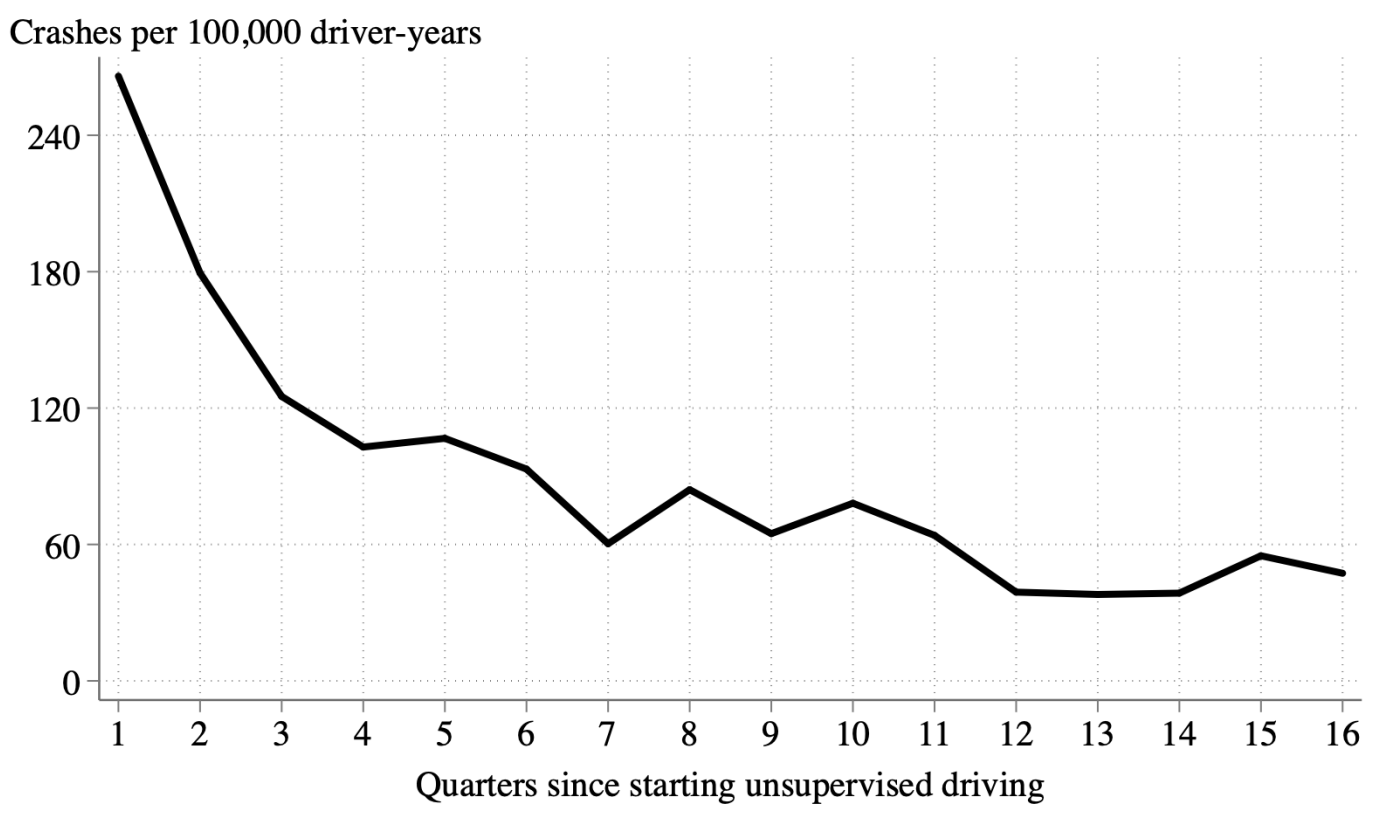

Notes: These figures show the crash rates as a function of driving experience before the introduction of the nighttime passenger restriction in NSW. Experience is the number of quarters since a probation (P1) license was first held. The sample includes crash records from June 2004 to June 2007 for all drivers who obtained a P1 license before age 24 , which matches the sample restriction for our main sample. 
Figure A3: Changes in crash rates of first-year drivers relative to the six months before the introduction of the nighttime passenger restriction, by number of passengers and time of day

(a) 2+ passengers, 11:00pm-4:59am

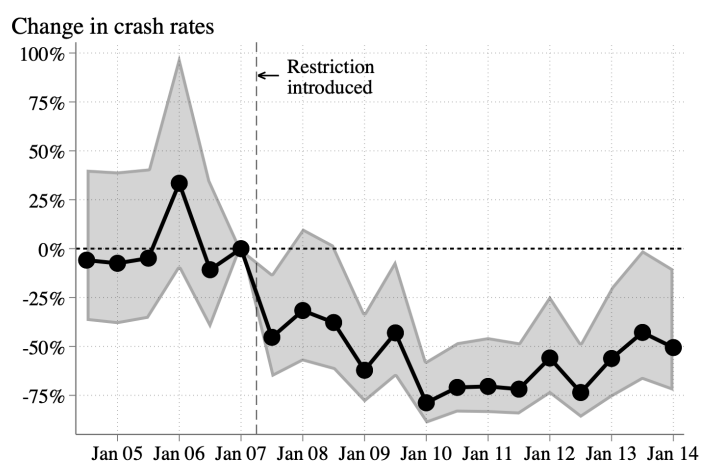

(c) 2+ passengers, 8:00pm-10:59pm

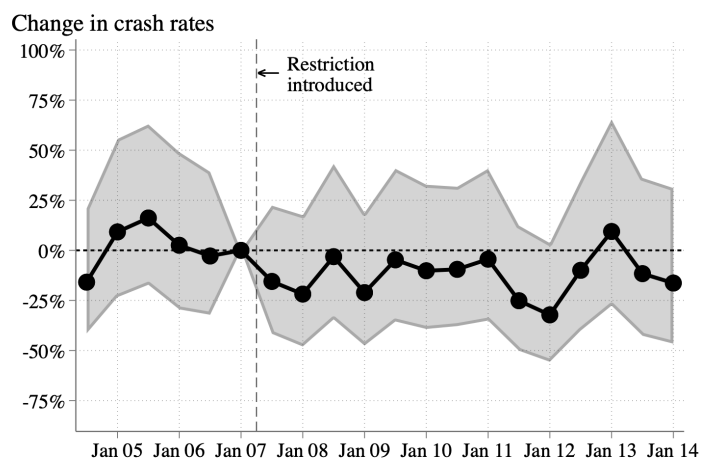

(e) 2+ passengers, 5:00am-7:59am

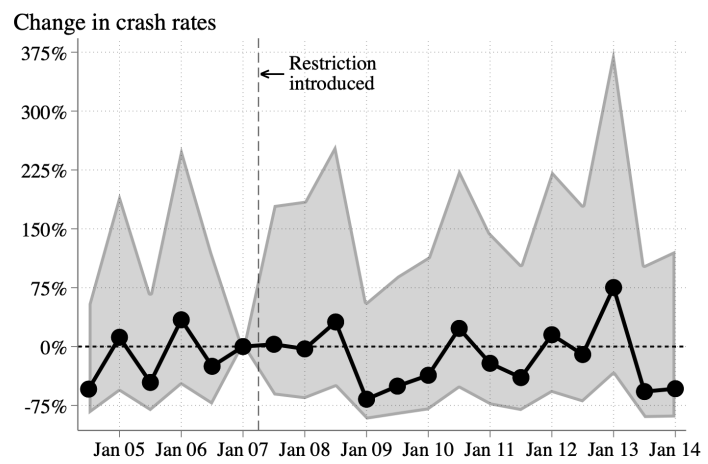

(b) 0/1 passenger, 11:00pm-4:59am

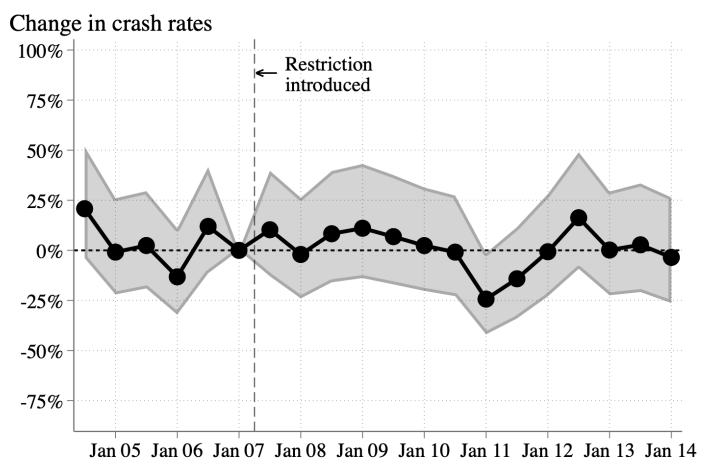

(d) 0/1 passenger, 8:00pm-10:59pm

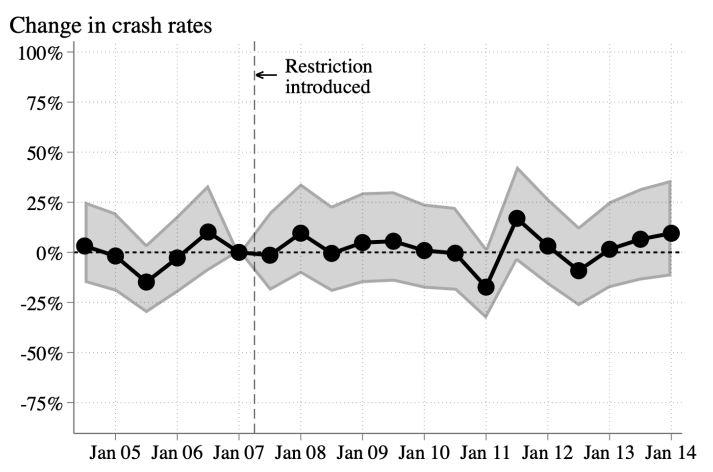

(f) 0/1 passenger, 5:00am-7:59am

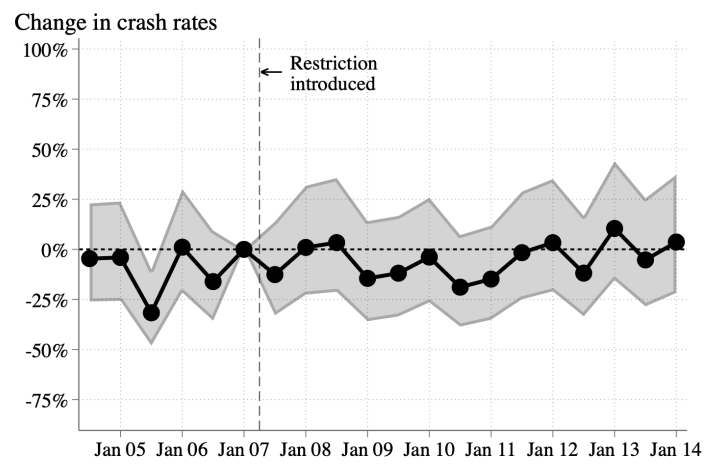

Notes: These figures show the percentage changes in crash rates, with $95 \%$ confidence intervals, of first-year drivers in different periods of the day relative to daytime crashes and the six months before the restriction was introduced. The specification is similar to equation (1), except we interact the period-of-day dummy variables with dummies spanning six-month periods. We use driver-license and crash data from July 2004 to June 2014 and our estimates come from separate regressions for multi-passenger crashes [panels (a), (c) and (e)] and crashes with 0/1 passenger [panels (b), (d) and (f)]. Panel (a) shows that there are no changes in multi-passenger crashes during 11:00pm-4:59am before the restriction and large, statistically significant reductions afterwards. Panel (b) shows no changes over time in crashes with 0/1 passenger during 11:00pm-4:59am. Both figures are consistent with the crash rates in Figure 1. The other panels show no statistically significant differences in crash rates in the evening and morning periods, although all but one of the post-restriction estimates for multi-passenger crashes in the evening period imply a reduction in crash rates. 
Figure A4: Estimated change in crash rates of first-year drivers in three-hour windows

(a) Carrying two or more passengers

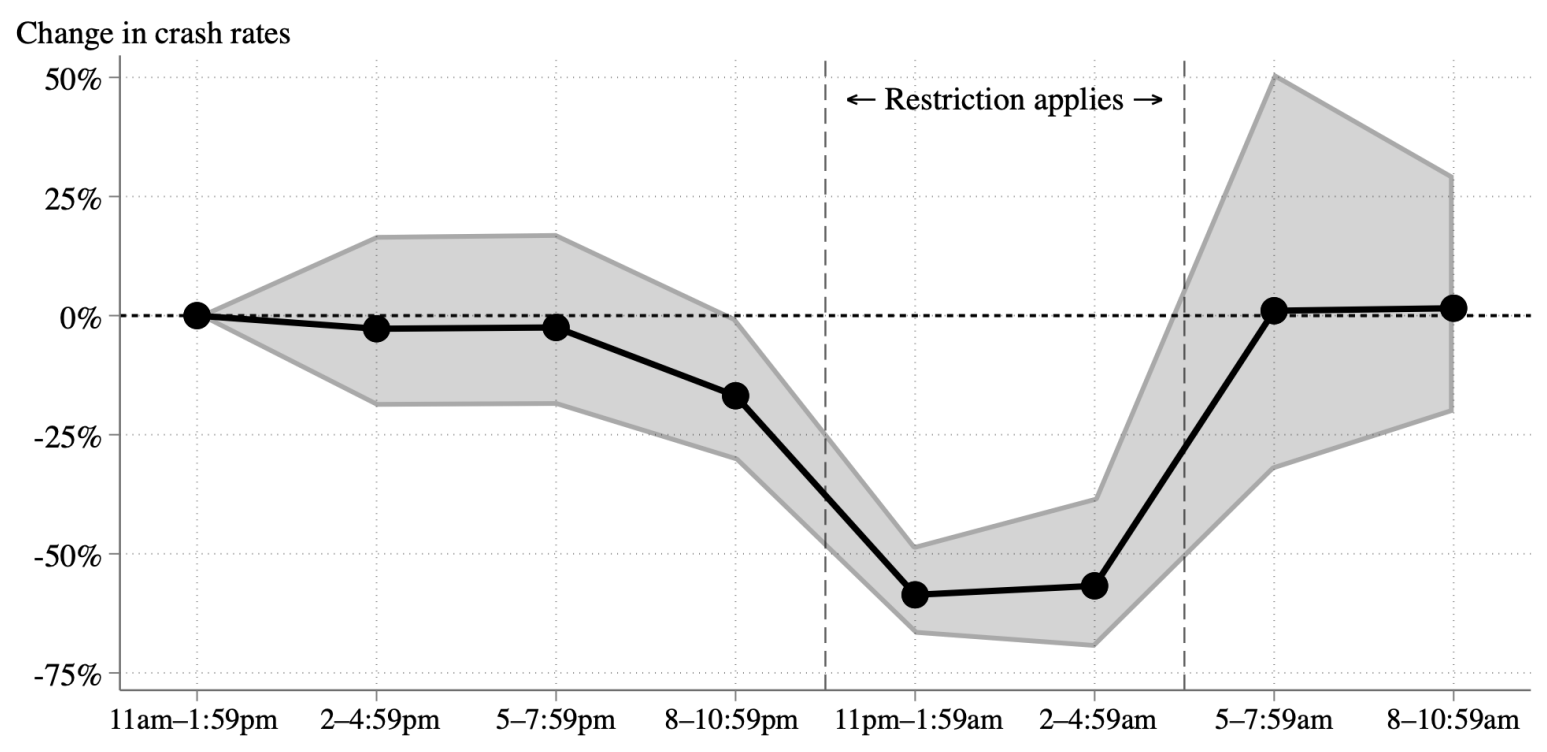

(b) Carrying zero or one passenger

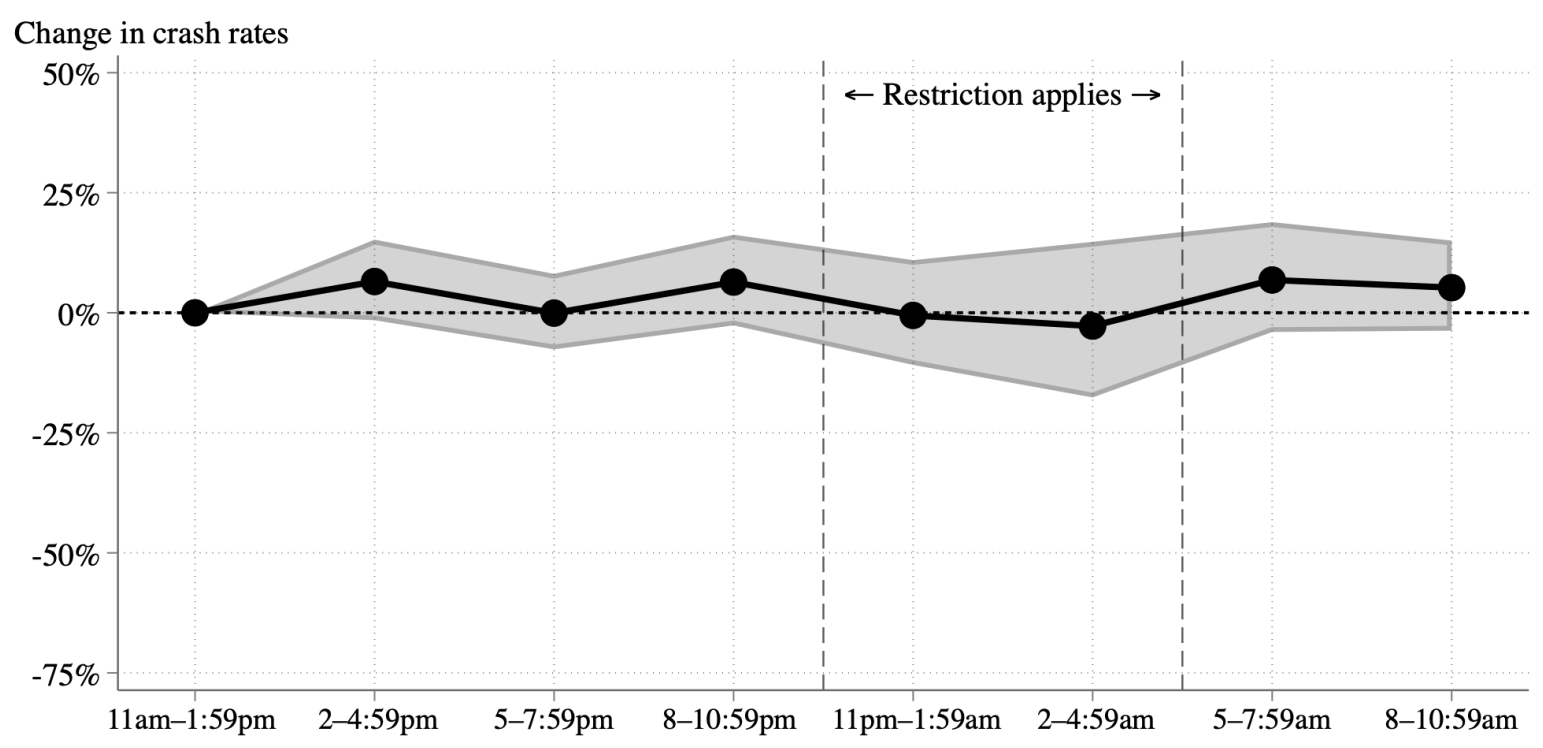

Notes: These figures show the implied percentage changes and $95 \%$ confidence intervals in the crash rates of firstyear drivers in three-hour periods of the day after the nighttime passenger restriction was introduced, relative to a 11:00am-1:59pm reference period. The estimates come from a version of equation (1) where the three period-ofday indicator variables are replaced with seven indicator variables identifying three-hour periods across the day. These estimates are based on the same data. Panel (a) shows the estimates for multi-passenger crashes. There is a similar percentage reduction in crashes in the first three hours and second three hours of the restricted period, which are also similar to the main estimate in Table 1. There is a reduction in crashes in the three hours before the restricted period. Otherwise, the estimates are close to zero and not statistically significant. Panel (b) shows the estimates for crashes with zero or one passenger. All of the estimates are close to zero and not statistically significant. 
Figure A5: Average crash rates of first-year drivers by hour before and after the reform by number of passengers

(a) Crash rates: $2+$ passengers

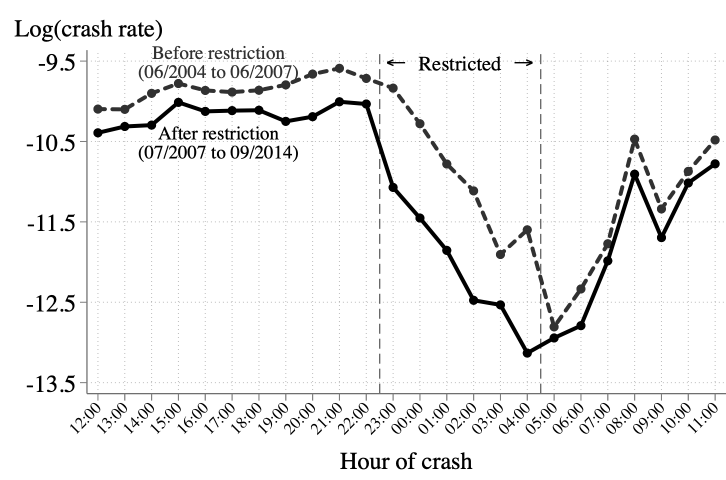

(c) Crash rates: 0/1 passenger

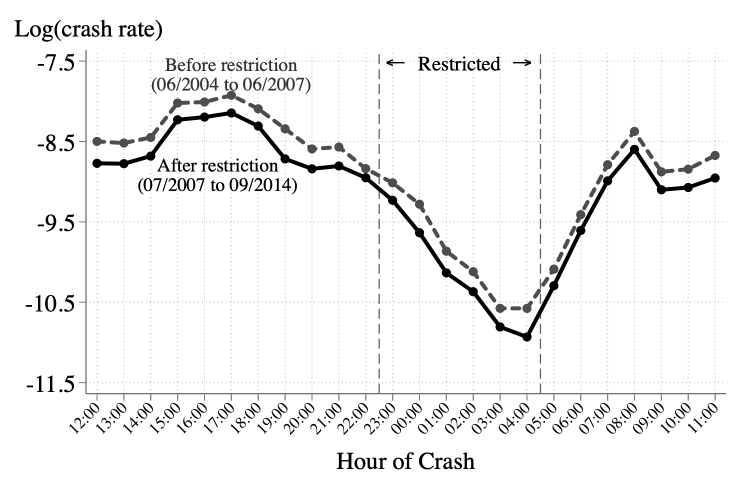

(b) Change in crash rates: $2+$ passengers

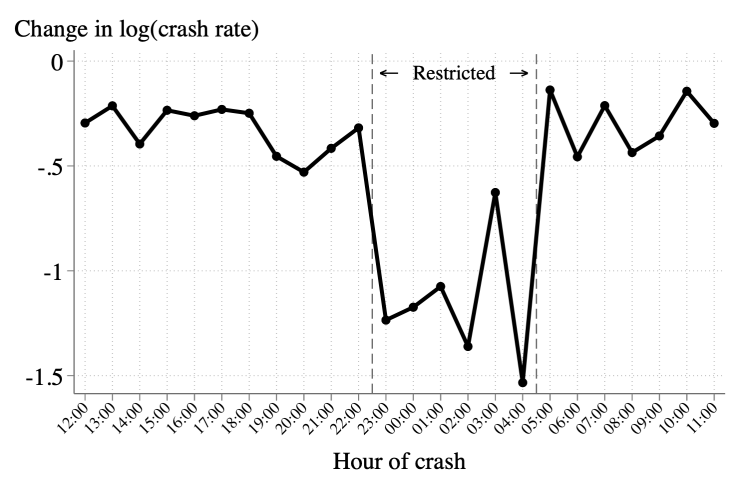

(d) Change in crash rates: 0/1 passenger

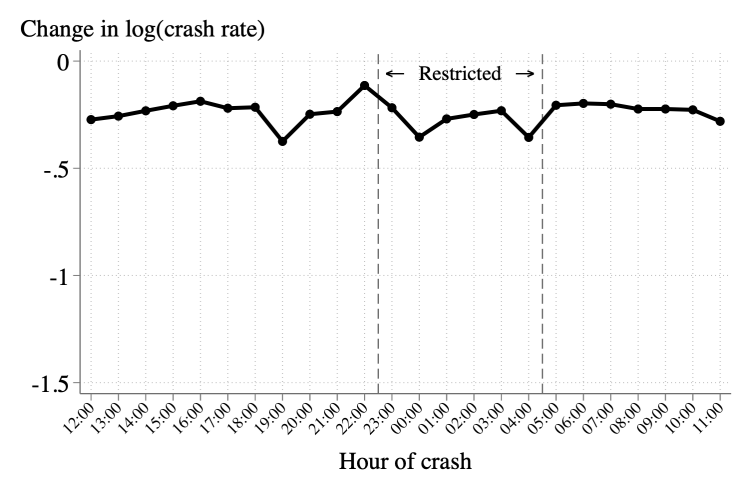

Notes: These figures show the log of the hourly crash rates before and after the introduction of the nighttime passenger restriction in July 2007. Panel (a) shows the rates for multi-passenger crashes. There is a reduction in crashes across the day, but the reduction is much larger in the 11:00pm to 4:59am hours than in the rest of the day. Panel (b) shows the change in the rates in panel (a), which confirms that the largest differences occur in the restricted period. The differences in the earlier evening hours are the next largest, while the differences in other hours are fairly similar. Panels (c) and (d) show the equivalent information for crashes with zero or one passenger. There is little visual evidence of these crashes having a different pattern in or near the restricted period to other hours of the day. 
Figure A6: Trends in the annual rate of new first-year (P1) licenses by age

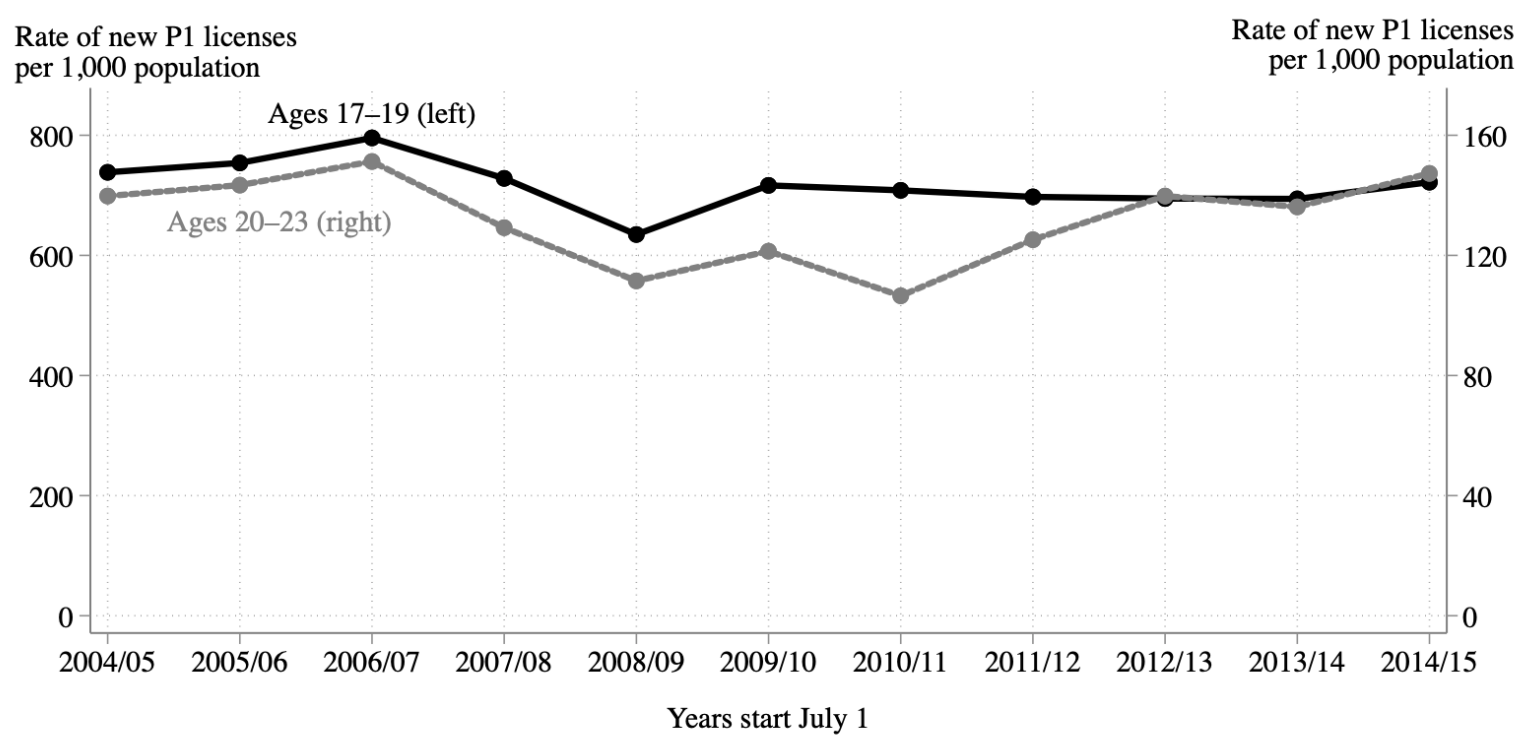

Notes: This figure shows the annual rate of new P1 licenses per 1,000 population in NSW by age. The figure shows a small decline in the license rate after the nighttime peer-passenger restriction is introduced in July 2007. The relative decline is largest among individuals aged 20-23 years, who are less likely to be constrained by the nighttime peer-passenger restriction (assuming they have friends of a similar age). This suggests that the restriction had no large impacts on the license rate. 
Figure A7: The relationship between first-year and longer-term treatment effect heterogeneity

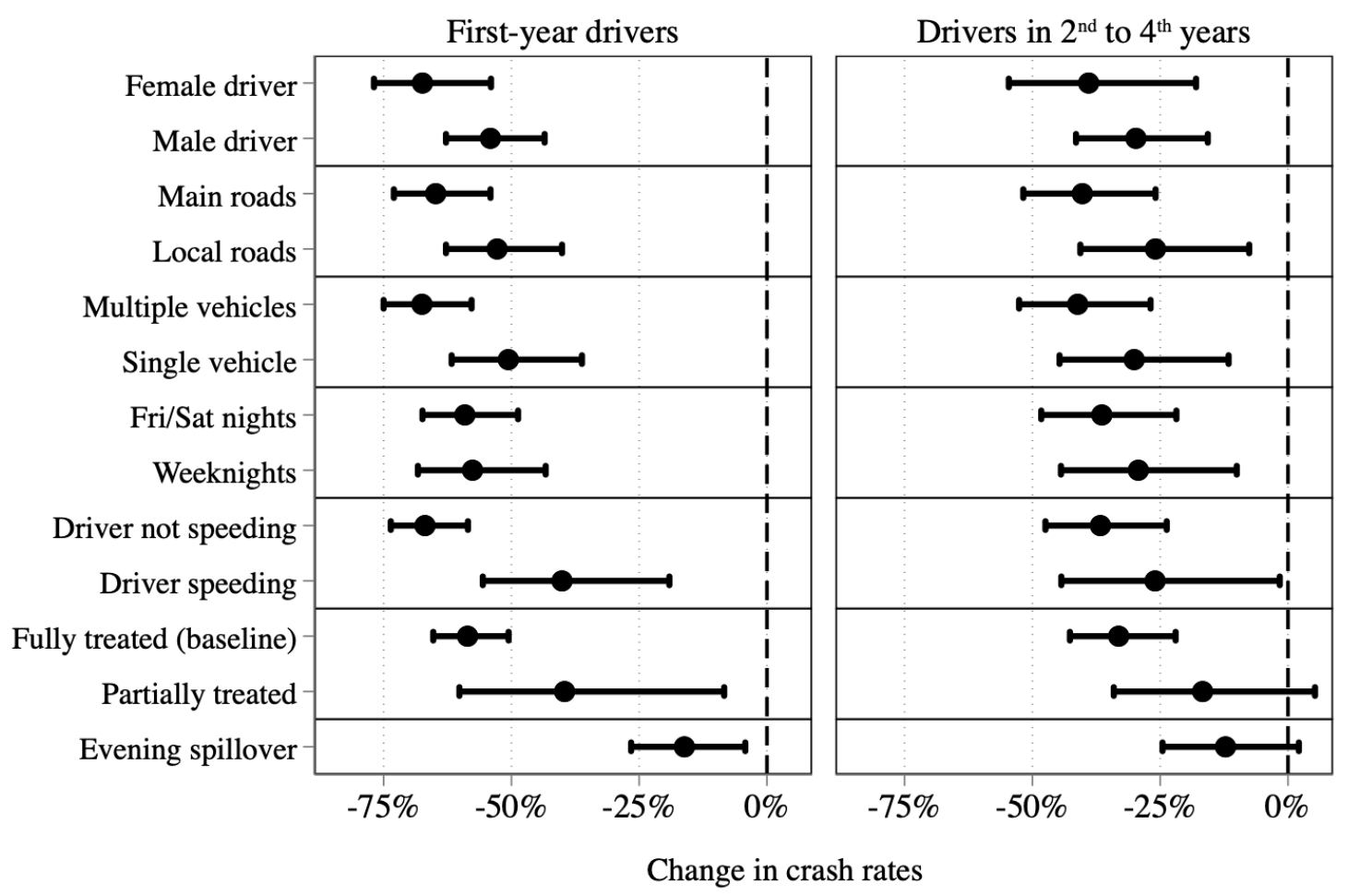

Notes: The figures show the treatment effect heterogeneity estimates for multi-passenger crashes in the restricted window (11:00pm-4:59am) in the first year of driving and the average for the next three years. We also present the "evening spillover" effect on multi-passenger crashes in the 8:00pm-10:59pm period to facilitate comparisons to the overall effect in the restricted period ("fully treated (baseline)"). The estimates are based on equation (2) with a sample of never treated and fully treated drivers (except for the partially treated estimate, which includes partially treated and excludes fully treated drivers). The longer-term estimates on the right are a weighted average of the effects in years 2-4 based on the crash rates in each year of driving (and standard errors calculated using the delta method). All estimates use driver-license and crash data from June 2004 to September 2014. The point estimates are the same as in Figure 4; this figure adds the $95 \%$ confidence intervals. 
Table A1: Pre-reform license and crash characteristics of first-year drivers

\begin{tabular}{|c|c|c|c|}
\hline & \multirow[b]{2}{*}{$\begin{array}{l}\text { Licenses } \\
\text { (1) }\end{array}$} & \multicolumn{2}{|c|}{ Crashes } \\
\hline & & $\begin{array}{l}\text { All } \\
(2)\end{array}$ & $\begin{array}{c}2+\text { passengers \& } \\
11 \mathrm{pm}-4: 59 \mathrm{am} \\
(3)\end{array}$ \\
\hline \multicolumn{4}{|l|}{$\underline{\text { License characteristics }}$} \\
\hline Male & $51.7 \%$ & $62.1 \%$ & $70.8 \%$ \\
\hline $\begin{array}{l}\text { Age } \\
\text { (Std. dev) }\end{array}$ & $\begin{array}{l}18.8 \\
(1.7)\end{array}$ & $\begin{array}{l}18.1 \\
(1.5)\end{array}$ & $\begin{array}{l}17.7 \\
(1.2)\end{array}$ \\
\hline $\begin{array}{l}\text { Months held license } \\
\text { (Std. dev) }\end{array}$ & $\begin{array}{c}5.4 \\
(3.5)\end{array}$ & $\begin{array}{c}4.9 \\
(3.3)\end{array}$ & $\begin{array}{c}4.5 \\
(3.3)\end{array}$ \\
\hline Unique drivers & 315,837 & 13,056 & 377 \\
\hline \multicolumn{4}{|l|}{ Crash characteristics } \\
\hline $\begin{array}{l}\text { Number of casualties } \\
\text { (Std. dev) }\end{array}$ & & $\begin{array}{c}0.58 \\
(0.89)\end{array}$ & $\begin{array}{c}0.85 \\
(1.79)\end{array}$ \\
\hline $\begin{array}{l}\text { Number hospitalized } \\
\text { (Std. dev) }\end{array}$ & & $\begin{array}{c}0.089 \\
(0.354)\end{array}$ & $\begin{array}{c}0.220 \\
(0.701)\end{array}$ \\
\hline $\begin{array}{l}\text { Number killed } \\
\text { (Std. dev) }\end{array}$ & & $\begin{array}{c}0.0054 \\
(0.0860)\end{array}$ & $\begin{array}{c}0.0371 \\
(0.2894)\end{array}$ \\
\hline $\begin{array}{l}\text { Number of passengers } \\
\text { (Std. dev) }\end{array}$ & & $\begin{array}{c}0.7 \\
(1.0)\end{array}$ & $\begin{array}{c}2.8 \\
(0.9)\end{array}$ \\
\hline $\begin{array}{l}\text { Number of vehicles } \\
\text { (Std. dev) }\end{array}$ & & $\begin{array}{l}1.9 \\
(0.8)\end{array}$ & $\begin{array}{l}1.6 \\
(0.6)\end{array}$ \\
\hline Weekend (Friday 5:00am to Sunday 4:59am) & & $35.5 \%$ & $66.0 \%$ \\
\hline Daytime period: 8:00am-7:59pm & & $69.1 \%$ & $0 \%$ \\
\hline Restricted period: 11:00pm-4:59am & & $10.2 \%$ & $100 \%$ \\
\hline Evening period: $8: 00-10: 59 \mathrm{pm}$ & & $14.6 \%$ & $0 \%$ \\
\hline Morning period: 5:00-7:59am & & $6.1 \%$ & $0 \%$ \\
\hline In Sydney & & $55.7 \%$ & $58.9 \%$ \\
\hline In other urban area & & $36.6 \%$ & $34.5 \%$ \\
\hline Main road & & $51.4 \%$ & $48.8 \%$ \\
\hline Local road & & $48.6 \%$ & $51.2 \%$ \\
\hline First-year driver speeding & & $19.3 \%$ & $33.7 \%$ \\
\hline First-year driver had alcohol & & $2.0 \%$ & $9.5 \%$ \\
\hline Most responsible driver (police judgment) & & $76.2 \%$ & $84.1 \%$ \\
\hline
\end{tabular}

Notes: This table summarizes the driver-license and crash records of first-year drivers prior to the reform. The sample comes from linked administrative driver-license and crash records from June 2004 to June 2007. 
Table A2: Effect of varying spillover periods for multi-passenger crash outcomes

\begin{tabular}{|c|c|c|c|}
\hline & \multicolumn{3}{|c|}{ Hours in each spillover period } \\
\hline & 2 & 3 & 4 \\
\hline & \multicolumn{3}{|c|}{ Crashes } \\
\hline Evening spillover & $\begin{array}{c}-0.133 \\
(0.077)\end{array}$ & $\begin{array}{c}-0.166 \\
(0.067)\end{array}$ & $\begin{array}{c}-0.173 \\
(0.063)\end{array}$ \\
\hline \multirow[t]{2}{*}{ Morning spillover } & $\begin{array}{l}-0.064 \\
(0.277)\end{array}$ & $\begin{array}{c}0.036 \\
(0.193)\end{array}$ & $\begin{array}{l}-0.035 \\
(0.124)\end{array}$ \\
\hline & \multicolumn{3}{|c|}{ Number of casualties } \\
\hline Evening spillover & $\begin{array}{l}-0.311 \\
(0.141)\end{array}$ & $\begin{array}{c}-0.300 \\
(0.121)\end{array}$ & $\begin{array}{c}-0.324 \\
(0.113)\end{array}$ \\
\hline \multirow[t]{2}{*}{ Morning spillover } & $\begin{array}{l}-0.150 \\
(0.523)\end{array}$ & $\begin{array}{c}-0.073 \\
(0.351)\end{array}$ & $\begin{array}{l}-0.158 \\
(0.223)\end{array}$ \\
\hline & \multicolumn{3}{|c|}{ Number in hospital/killed } \\
\hline Evening spillover & $\begin{array}{l}-0.367 \\
(0.284)\end{array}$ & $\begin{array}{l}-0.427 \\
(0.243)\end{array}$ & $\begin{array}{l}-0.732 \\
(0.232)\end{array}$ \\
\hline Morning spillover & $\begin{array}{l}-0.783 \\
(0.652)\end{array}$ & $\begin{array}{l}-0.042 \\
(0.582)\end{array}$ & $\begin{array}{l}-0.518 \\
(0.473)\end{array}$ \\
\hline
\end{tabular}

Notes: This table presents Poisson regression estimates using different lengths of time to measure the spillover effects of the nighttime passenger restriction on the multi-passenger crash outcomes of first-year drivers in hours just outside the restricted period. Equation (1) uses three-hour periods, denoted as the evening and morning periods. We present results using respective periods of two, three and four hours in columns (1), (2) and (3). The first two estimates come from regressions using a daytime reference period of 8:00am-7:59pm, while the third necessarily uses a narrower reference period of 9:00am-6:59pm to avoid overlap with the four-hour spillover periods. We estimate but do not report results for the restricted period. All regressions use the same controls; see Table 1 notes and the text for details. The sample comes from linked administrative driver-license and crash records from June 2004 to September 2014, and the number of observations in each regression is $38,454,512$. The estimated changes in crash outcomes are similar across periods spanning two, three and four hours, with the differences from zero becoming more statistically significant as the number of hours increase. These results show that the estimates are robust to choices around how spillovers are measured. This is consistent with Figure A5, which shows the hourly crash rates before and after the restriction was introduced. 
Table A3: Robustness of main estimates to choice of regression model

\begin{tabular}{|c|c|c|c|c|c|c|}
\hline & \multicolumn{3}{|c|}{$\begin{array}{c}\text { Main estimates } \\
\text { (Carrying } 2+\text { passengers) }\end{array}$} & \multicolumn{3}{|c|}{$\begin{array}{l}\text { Estimates for } 0-1 \\
\text { passenger crashes }\end{array}$} \\
\hline & $\begin{array}{c}\text { All } \\
\text { crashes } \\
(1)\end{array}$ & $\begin{array}{c}\text { No. of } \\
\text { casualties } \\
(2)\end{array}$ & $\begin{array}{c}\text { No. in } \\
\text { hospital/ } \\
\text { killed } \\
(3)\end{array}$ & $\begin{array}{c}\text { All } \\
\text { crashes } \\
(4)\end{array}$ & $\begin{array}{c}\text { No. of } \\
\text { casualties } \\
(5)\end{array}$ & $\begin{array}{c}\text { No. in } \\
\text { hospital/ } \\
\text { killed } \\
(6)\end{array}$ \\
\hline \multicolumn{7}{|c|}{ Panel A: Poisson with robust standard errors (without individual-level clustering) } \\
\hline Direct effect: $11 \mathrm{pm}-4: 59 \mathrm{am}$ & $\begin{array}{l}-0.846 \\
(0.087)\end{array}$ & $\begin{array}{l}-0.696 \\
(0.168)\end{array}$ & $\begin{array}{l}-0.858 \\
(0.268)\end{array}$ & $\begin{array}{l}-0.036 \\
(0.042)\end{array}$ & $\begin{array}{l}-0.064 \\
(0.075)\end{array}$ & $\begin{array}{l}-0.240 \\
(0.137)\end{array}$ \\
\hline Evening spillover: 8-10:59pm & $\begin{array}{l}-0.166 \\
(0.067)\end{array}$ & $\begin{array}{l}-0.300 \\
(0.121)\end{array}$ & $\begin{array}{l}-0.427 \\
(0.242)\end{array}$ & $\begin{array}{c}0.031 \\
(0.036)\end{array}$ & $\begin{array}{l}-0.001 \\
(0.063)\end{array}$ & $\begin{array}{l}-0.067 \\
(0.134)\end{array}$ \\
\hline Morning spillover: 5-7:59am & $\begin{array}{c}0.036 \\
(0.193)\end{array}$ & $\begin{array}{l}-0.073 \\
(0.351)\end{array}$ & $\begin{array}{l}-0.042 \\
(0.582)\end{array}$ & $\begin{array}{c}0.045 \\
(0.047)\end{array}$ & $\begin{array}{c}0.100 \\
(0.078)\end{array}$ & $\begin{array}{l}-0.076 \\
(0.169)\end{array}$ \\
\hline \multicolumn{7}{|c|}{ Panel B: Negative Binomial } \\
\hline Direct effect: $11 \mathrm{pm}-4: 59 \mathrm{am}$ & $\begin{array}{l}-0.845 \\
(0.087)\end{array}$ & $\begin{array}{l}-0.691 \\
(0.144)\end{array}$ & $\begin{array}{l}-1.068 \\
(0.217)\end{array}$ & $\begin{array}{l}-0.036 \\
(0.042)\end{array}$ & $\begin{array}{l}-0.064 \\
(0.074)\end{array}$ & $\begin{array}{l}-0.254 \\
(0.133)\end{array}$ \\
\hline Evening spillover: $8-10: 59 \mathrm{pm}$ & $\begin{array}{l}-0.164 \\
(0.067)\end{array}$ & $\begin{array}{l}-0.313 \\
(0.118)\end{array}$ & $\begin{array}{l}-0.550 \\
(0.198)\end{array}$ & $\begin{array}{c}0.033 \\
(0.036)\end{array}$ & $\begin{array}{c}-0.005 \\
(0.062)\end{array}$ & $\begin{array}{c}-0.078 \\
(0.129)\end{array}$ \\
\hline Morning spillover: 5-7:59am & $\begin{array}{c}0.043 \\
(0.193)\end{array}$ & $\begin{array}{c}-0.115 \\
(0.283)\end{array}$ & $\begin{array}{c}-0.236 \\
(0.411)\end{array}$ & $\begin{array}{c}0.044 \\
(0.047)\end{array}$ & $\begin{array}{c}0.094 \\
(0.077)\end{array}$ & $\begin{array}{c}-0.080 \\
(0.160)\end{array}$ \\
\hline \multicolumn{7}{|c|}{ Panel C: Poisson (aggregate count) } \\
\hline Direct effect: $11 \mathrm{pm}-4: 59 \mathrm{am}$ & $\begin{array}{l}-0.846 \\
(0.080)\end{array}$ & $\begin{array}{c}-0.703 \\
(0.135)\end{array}$ & $\begin{array}{c}-0.905 \\
(0.230)\end{array}$ & $\begin{array}{c}-0.038 \\
(0.035)\end{array}$ & $\begin{array}{c}-0.065 \\
(0.071)\end{array}$ & $\begin{array}{l}-0.230 \\
(0.112)\end{array}$ \\
\hline Evening spillover: $8-10: 59 \mathrm{pm}$ & $\begin{array}{l}-0.170 \\
(0.054)\end{array}$ & $\begin{array}{c}-0.296 \\
(0.102)\end{array}$ & $\begin{array}{c}-0.412 \\
(0.196)\end{array}$ & $\begin{array}{c}0.027 \\
(0.031)\end{array}$ & $\begin{array}{c}-0.004 \\
(0.055)\end{array}$ & $\begin{array}{l}-0.062 \\
(0.122)\end{array}$ \\
\hline Morning spillover: 5-7:59am & $\begin{array}{c}0.051 \\
(0.160)\end{array}$ & $\begin{array}{c}-0.115 \\
(0.297)\end{array}$ & $\begin{array}{c}-0.109 \\
(0.521)\end{array}$ & $\begin{array}{c}0.046 \\
(0.041)\end{array}$ & $\begin{array}{c}0.098 \\
(0.077)\end{array}$ & $\begin{array}{c}-0.074 \\
(0.155)\end{array}$ \\
\hline \multicolumn{7}{|c|}{ Panel D: Log (aggregate count +1$)$} \\
\hline Direct effect: $11 \mathrm{pm}-4: 59 \mathrm{am}$ & $\begin{array}{l}-0.735 \\
(0.085)\end{array}$ & $\begin{array}{c}-0.609 \\
(0.151)\end{array}$ & $\begin{array}{c}-0.557 \\
(0.198)\end{array}$ & $\begin{array}{c}-0.027 \\
(0.045)\end{array}$ & $\begin{array}{c}-0.046 \\
(0.086)\end{array}$ & $\begin{array}{l}-0.461 \\
(0.145)\end{array}$ \\
\hline Evening spillover: $8-10: 59 \mathrm{pm}$ & $\begin{array}{c}-0.154 \\
(0.078)\end{array}$ & $\begin{array}{c}-0.323 \\
(0.149)\end{array}$ & $\begin{array}{c}-0.416 \\
(0.183)\end{array}$ & $\begin{array}{c}0.026 \\
(0.041)\end{array}$ & $\begin{array}{c}0.003 \\
(0.076)\end{array}$ & $\begin{array}{c}-0.198 \\
(0.149)\end{array}$ \\
\hline Morning spillover: 5-7:59am & $\begin{array}{c}0.156 \\
(0.092)\end{array}$ & $\begin{array}{c}0.045 \\
(0.152)\end{array}$ & $\begin{array}{c}-0.192 \\
(0.174)\end{array}$ & $\begin{array}{c}0.065 \\
(0.052)\end{array}$ & $\begin{array}{c}0.123 \\
(0.089)\end{array}$ & $\begin{array}{c}-0.289 \\
(0.161)\end{array}$ \\
\hline
\end{tabular}

Notes: This table compares the estimates from different specifications of the effects of the nighttime passenger restriction on the crash outcomes of first-year drivers. Panel A reproduces the individual-level Poisson estimates in Table 1 but with robust standard errors in parentheses. Panel B shows the estimates from an equivalent Negative Binomial model (with individual-level clustering). Each regression in these panels uses 38,454,512 observations at the driver-month-year-period level. The regressions in Panels C and D use 496 observations at the month-year-period level with robust standard errors. This requires us to drop individuallevel controls, but all other controls are maintained. Panel $\mathrm{C}$ shows Poisson estimates and Panel D shows OLS estimates where the dependent variable is transformed from $y$ to $\ln (y+1)$. See the notes in Table 1 and the text for more details. The table shows that the estimates are similar across all specifications. 
Table A4: Robustness of main estimates to different samples

\begin{tabular}{|c|c|c|c|c|c|c|}
\hline & \multicolumn{3}{|c|}{$\begin{array}{c}\text { Main estimates } \\
\text { (Carrying } 2+\text { passengers) }\end{array}$} & \multicolumn{3}{|c|}{$\begin{array}{l}\text { Estimates for } 0-1 \\
\text { passenger crashes }\end{array}$} \\
\hline & $\begin{array}{c}\text { All } \\
\text { crashes } \\
(1)\end{array}$ & $\begin{array}{c}\text { No. of } \\
\text { casualties } \\
(2)\end{array}$ & $\begin{array}{c}\text { No. in } \\
\text { hospital/ } \\
\text { killed } \\
(3)\end{array}$ & $\begin{array}{c}\text { All } \\
\text { crashes } \\
(4)\end{array}$ & $\begin{array}{c}\text { No. of } \\
\text { casualties } \\
(5)\end{array}$ & $\begin{array}{l}\text { No. in } \\
\text { hospital/ } \\
\text { killed } \\
(6)\end{array}$ \\
\hline \multicolumn{7}{|c|}{ Panel A: First-year drivers (main sample) } \\
\hline Direct effect: $11 \mathrm{pm}-4: 59 \mathrm{am}$ & $\begin{array}{l}-0.846 \\
(0.087)\end{array}$ & $\begin{array}{l}-0.696 \\
(0.167)\end{array}$ & $\begin{array}{l}-0.858 \\
(0.268)\end{array}$ & $\begin{array}{l}-0.036 \\
(0.042)\end{array}$ & $\begin{array}{l}-0.064 \\
(0.075)\end{array}$ & $\begin{array}{l}-0.240 \\
(0.137)\end{array}$ \\
\hline Implied percent change & $-57.1 \%$ & $-50.1 \%$ & $-57.6 \%$ & $-3.5 \%$ & $-6.2 \%$ & $-21.3 \%$ \\
\hline Evening spillover: 8-10:59pm & $\begin{array}{l}-0.166 \\
(0.067)\end{array}$ & $\begin{array}{l}-0.300 \\
(0.121)\end{array}$ & $\begin{array}{l}-0.427 \\
(0.243)\end{array}$ & $\begin{array}{c}0.031 \\
(0.036)\end{array}$ & $\begin{array}{l}-0.001 \\
(0.063)\end{array}$ & $\begin{array}{l}-0.067 \\
(0.134)\end{array}$ \\
\hline Implied percent change & $-15.3 \%$ & $-25.9 \%$ & $-34.7 \%$ & $3.2 \%$ & $-0.1 \%$ & $-6.5 \%$ \\
\hline Morning spillover: 5-7:59am & $\begin{array}{c}0.036 \\
(0.193)\end{array}$ & $\begin{array}{l}-0.073 \\
(0.351)\end{array}$ & $\begin{array}{l}-0.042 \\
(0.582)\end{array}$ & $\begin{array}{c}0.045 \\
(0.047)\end{array}$ & $\begin{array}{c}0.100 \\
(0.078)\end{array}$ & $\begin{array}{l}-0.076 \\
(0.169)\end{array}$ \\
\hline Implied percent change & $3.6 \%$ & $-7.1 \%$ & $-4.1 \%$ & $4.6 \%$ & $10.6 \%$ & $-7.3 \%$ \\
\hline \multicolumn{7}{|c|}{ Panel B: First-year drivers who got licenses by age 19} \\
\hline Direct effect: $11 \mathrm{pm}-4: 59 \mathrm{am}$ & $\begin{array}{c}-0.880^{* * *} \\
(0.091)\end{array}$ & $\begin{array}{c}-0.722^{* * *} \\
(0.175)\end{array}$ & $\begin{array}{c}-0.959^{* * *} \\
(0.283)\end{array}$ & $\begin{array}{l}-0.034 \\
(0.045)\end{array}$ & $\begin{array}{l}-0.101 \\
(0.080)\end{array}$ & $\begin{array}{c}-0.293^{* *} \\
(0.145)\end{array}$ \\
\hline Implied percent change & $-58.5 \%$ & $-51.4 \%$ & $-61.7 \%$ & $-3.4 \%$ & $-9.6 \%$ & $-25.4 \%$ \\
\hline Evening spillover: $8-10: 59 \mathrm{pm}$ & $\begin{array}{c}-0.162^{* *} \\
(0.069)\end{array}$ & $\begin{array}{c}-0.254^{* *} \\
(0.125)\end{array}$ & $\begin{array}{l}-0.437 \\
(0.253)\end{array}$ & $\begin{array}{c}0.036 \\
(0.038)\end{array}$ & $\begin{array}{c}-0.029 \\
(0.068)\end{array}$ & $\begin{array}{l}-0.044 \\
(0.143)\end{array}$ \\
\hline Implied percent change & $-15.0 \%$ & $-22.4 \%$ & $-35.4 \%$ & $3.6 \%$ & $-2.9 \%$ & $-4.3 \%$ \\
\hline Morning spillover: 5-7:59am & $\begin{array}{c}0.028 \\
(0.203)\end{array}$ & $\begin{array}{l}-0.063 \\
(0.366)\end{array}$ & $\begin{array}{l}-0.073 \\
(0.638)\end{array}$ & $\begin{array}{c}0.049 \\
(0.051)\end{array}$ & $\begin{array}{c}0.098 \\
(0.085)\end{array}$ & $\begin{array}{l}-0.138 \\
(0.183)\end{array}$ \\
\hline Implied percent change & $2.8 \%$ & $-6.1 \%$ & $-7.1 \%$ & $5.0 \%$ & $10.3 \%$ & $-12.9 \%$ \\
\hline \multicolumn{7}{|c|}{ Panel C: All P1 drivers aged under 25} \\
\hline Direct effect: $11 \mathrm{pm}-4: 59 \mathrm{am}$ & $\begin{array}{l}-0.810 \\
(0.076)\end{array}$ & $\begin{array}{l}-0.722 \\
(0.143)\end{array}$ & $\begin{array}{l}-0.748 \\
(0.232)\end{array}$ & $\begin{array}{l}-0.017 \\
(0.037)\end{array}$ & $\begin{array}{l}-0.022 \\
(0.065)\end{array}$ & $\begin{array}{l}-0.198 \\
(0.117)\end{array}$ \\
\hline Implied percent change & $-55.5 \%$ & $-51.4 \%$ & $-52.6 \%$ & $-1.7 \%$ & $-2.2 \%$ & $-17.9 \%$ \\
\hline Evening spillover: 8-10:59pm & $\begin{array}{l}-0.151 \\
(0.061)\end{array}$ & $\begin{array}{c}-0.297 \\
(0.109)\end{array}$ & $\begin{array}{l}-0.431 \\
(0.215)\end{array}$ & $\begin{array}{c}0.025 \\
(0.031)\end{array}$ & $\begin{array}{c}0.002 \\
(0.055)\end{array}$ & $\begin{array}{l}-0.114 \\
(0.114)\end{array}$ \\
\hline Implied percent change & $-14.0 \%$ & $-25.7 \%$ & $-35.0 \%$ & $2.5 \%$ & $0.2 \%$ & $-10.8 \%$ \\
\hline Morning spillover: 5-7:59am & $\begin{array}{l}-0.040 \\
(0.164)\end{array}$ & $\begin{array}{c}-0.222 \\
(0.288)\end{array}$ & $\begin{array}{l}-0.458 \\
(0.451)\end{array}$ & $\begin{array}{c}0.067 \\
(0.040)\end{array}$ & $\begin{array}{c}0.165 \\
(0.067)\end{array}$ & $\begin{array}{c}0.118 \\
(0.142)\end{array}$ \\
\hline Implied percent change & $-3.9 \%$ & $-19.9 \%$ & $-36.7 \%$ & $6.9 \%$ & $17.9 \%$ & $12.5 \%$ \\
\hline
\end{tabular}

Notes: This table shows that the main estimates in Table 1 are similar if we restrict the sample to first-year drivers who got their license as teenagers (Panel B) or all P1 drivers aged under 25 (Panel C). The number of observations in each regression is 38,454,512 in Panel A, 32,524,248 in Panel B and 59,600,476 in Panel C. See the notes in Table 1 and the text for more details. 
Table A5: Placebo estimates for drivers aged 25+, who are not subject to the nighttime multipassenger restriction

\begin{tabular}{lcc}
\hline & $\begin{array}{c}\text { All crashes } \\
(1)\end{array}$ & $\begin{array}{c}\text { Single vehicle crashes } \\
(2)\end{array}$ \\
\hline Direct effect: 11pm-4:59am & 0.004 & -0.038 \\
& $(0.019)$ & $(0.026)$ \\
Implied percent change & $0.4 \%$ & $-3.7 \%$ \\
Evening spillover: 8-10:59pm & 0.018 & 0.017 \\
& $(0.016)$ & $(0.017)$ \\
Implied percent change & $1.8 \%$ & $1.7 \%$ \\
Morning spillover: 5-7:59am & 0.029 & 0.023 \\
Implied percent change & $(0.015)$ & $(0.017)$ \\
Observations & $3.0 \%$ & $2.4 \%$ \\
\hline
\end{tabular}

Notes: This table presents placebo estimates for drivers aged 25 and older. The Poisson estimates are based on a version of equation (1) with counts at the month-year-period level, as for this population we only have license information on drivers who were involved in crashes. This requires us to drop the individual-level controls in equation (1), but all other controls are maintained. Panel C of Table A3 shows that this approach results in similar estimates to our main regressions. In column (1), we include all crashes involving drivers aged $25+$, in order to understand whether changes in crash patterns across the day among older drivers may partially explain the decline in nighttime multi-passenger crashes among younger drivers. In column (2), we restrict the sample to single-vehicle crashes, as these crashes are arguably a cleaner measure of the crash risks of this group of older drivers. The estimates in both regressions show that there is no disproportionate change in the number of nighttime, evening and morning crashes involving drivers aged over 25 relative to the change during the daytime period $(8: 00 \mathrm{am}-7: 59 \mathrm{pm})$. These results add credibility to our parallel-trends assumption and further indicate that changes in nighttime multi-vehicle crashes among younger drivers are unlikely to be explained by changes in the driving behavior of older drivers. The sample comes from administrative crash records over the period from June 2004 to September 2014. 
Table A6: The impact of the nighttime passenger restriction on different road users

\begin{tabular}{|c|c|c|c|c|}
\hline & \multirow[b]{2}{*}{$\begin{array}{l}\text { Total } \\
(1)\end{array}$} & \multicolumn{2}{|c|}{ First-year driver's car } & \multirow[b]{2}{*}{$\begin{array}{c}\text { Other } \\
(4)\end{array}$} \\
\hline & & $\begin{array}{c}\text { Driver } \\
(2)\end{array}$ & $\begin{array}{c}\text { Passengers } \\
(3)\end{array}$ & \\
\hline & \multicolumn{4}{|c|}{ Number of casualties } \\
\hline Effect at 8pm-4:59am & $\begin{array}{c}-0.448 \\
(0.107)\end{array}$ & $\begin{array}{c}-0.340 \\
(0.122)\end{array}$ & $\begin{array}{l}-0.384 \\
(0.143)\end{array}$ & $\begin{array}{l}-0.644 \\
(0.158)\end{array}$ \\
\hline Implied percent change & $-36.1 \%$ & $-28.8 \%$ & $-31.9 \%$ & $-47.5 \%$ \\
\hline \multirow[t]{2}{*}{ Change per 100,000 drivers } & -98.2 & -21.8 & -41.3 & -28.8 \\
\hline & \multicolumn{4}{|c|}{ Number in hospital/killed } \\
\hline Effect at 8pm-4:59am & $\begin{array}{l}-0.628 \\
(0.206)\end{array}$ & $\begin{array}{c}-0.129 \\
(0.306)\end{array}$ & $\begin{array}{l}-0.543 \\
(0.264)\end{array}$ & $\begin{array}{l}-1.277 \\
(0.355)\end{array}$ \\
\hline Implied percent change & $-46.6 \%$ & $-12.1 \%$ & $-41.9 \%$ & $-72.1 \%$ \\
\hline Change per 100,000 drivers & -37.8 & -1.6 & -17.4 & -19.2 \\
\hline
\end{tabular}

Notes: This table presents the estimated changes in crash outcomes after the introduction of the nighttime passenger restriction for different road users. Estimates are based on a version of equation (1) with a combined evening and restricted period (8:00pm-4:59am). The Poisson estimates use daytime hours (8:00am-7:59pm) as the reference period. We allow for spillover effects on nearby hours in the morning but do not report these estimates (which are not statistically significant). The sample comes from linked administrative driver-license and crash records from June 2004 to September 2014. Estimates are based on separate regressions where a crash outcome is restricted to a specific group of road users (e.g., for the top panel of column (4), the dependent variable is the number of casualties among those outside of vehicles driven by first-year drivers: drivers/passengers in other vehicles and pedestrians). Each regression uses 28,840,884 observations, which is one-quarter less than in Table 1 because of the combined evening and restricted period. The results in this table show that first-year drivers account for a minority of the reductions in casualties and hospitalizations/deaths, with large benefits to other road users. 
Table A7: Impact of the restriction on teen casualties as non-peer passengers and pedestrians

\begin{tabular}{lccc}
\hline & $\begin{array}{c}\text { All non-drivers } \\
(1)\end{array}$ & $\begin{array}{c}\text { Non-peer passengers } \\
(2)\end{array}$ & $\begin{array}{c}\text { Pedestrians } \\
(3)\end{array}$ \\
\hline Direct effect: 11pm-4:59am & -0.102 & -0.108 & -0.065 \\
& $(0.058)$ & $(0.070)$ & $(0.090)$ \\
Implied percent change & $-9.7 \%$ & $-10.3 \%$ & $-6.3 \%$ \\
Change per 100,000 drivers & -9.9 & -7.9 & -1.6 \\
Evening spillover: 8pm-10:59pm & -0.037 & -0.046 & -0.014 \\
& $(0.073)$ & $(0.085)$ & $(0.119)$ \\
Implied percent change & $-3.6 \%$ & $-4.5 \%$ & $-1.4 \%$ \\
Change per 100,000 drivers & -2.4 & -2.2 & -0.2 \\
Morning spillover: 5-7:59am & -0.019 & 0.092 & -0.294 \\
& $(0.104)$ & $(0.125)$ & $(0.163)$ \\
Implied percent change & $-1.9 \%$ & $9.6 \%$ & $-25.5 \%$ \\
Change per 100,000 drivers & -0.5 & 1.9 & -2.3 \\
\hline
\end{tabular}

Notes: This table examines whether there was any increase in casualties among individuals aged 16-20 resulting from additional trips as pedestrians or non-peer passengers. The Poisson estimates are based on a version of equation (1) with casualty counts at the month-year-period level. Individual-level controls are not possible but all other controls are maintained. We exclude casualties from crashes that directly involve a P1 driver aged under 25 to avoid capturing any direct effects of the restriction. The number of observations in each regression is 496. The sample comes from administrative crash records and covers the period from June 2004 to September 2014. The estimates in this table are small and not statistically significant, suggesting that there were no large spillovers on casualties from additional trips as pedestrians or non-peer passengers. 
Table A8: Effect on nighttime multi-passenger crashes and casualties by year of driving

\begin{tabular}{|c|c|c|c|c|}
\hline & $\begin{array}{c}\text { All } \\
\text { crashes } \\
(1)\end{array}$ & $\begin{array}{c}\text { No. of } \\
\text { casualties } \\
(2)\end{array}$ & $\begin{array}{c}\text { No. in. } \\
\text { hospital/killed } \\
(3)\end{array}$ & $\begin{array}{c}\text { Property } \\
\text { damage only } \\
(4)\end{array}$ \\
\hline \multicolumn{5}{|l|}{ Direct effect: $11 \mathrm{pm}-4: 59 \mathrm{am}$} \\
\hline 1st year drivers & $\begin{array}{c}-0.881 \\
(0.090)\end{array}$ & $\begin{array}{l}-0.793 \\
(0.181)\end{array}$ & $\begin{array}{l}-0.990 \\
(0.277)\end{array}$ & $\begin{array}{l}-0.961 \\
(0.119)\end{array}$ \\
\hline Implied percent change & $-58.6 \%$ & $-54.7 \%$ & $-62.8 \%$ & $-61.8 \%$ \\
\hline Change per 100,000 drivers & -74.8 & -68.6 & -31.1 & -45.1 \\
\hline 2nd year drivers & $\begin{array}{c}-0.572 \\
(0.115)\end{array}$ & $\begin{array}{l}-0.408 \\
(0.190)\end{array}$ & $\begin{array}{l}-0.210 \\
(0.308)\end{array}$ & $\begin{array}{l}-0.588 \\
(0.163)\end{array}$ \\
\hline Implied percent change & $-43.5 \%$ & $-33.5 \%$ & $-18.9 \%$ & $-44.4 \%$ \\
\hline Change per 100,000 drivers & -27.2 & -18.4 & -2.6 & -13.5 \\
\hline 3rd year drivers & $\begin{array}{c}-0.270 \\
(0.131)\end{array}$ & $\begin{array}{l}-0.080 \\
(0.225)\end{array}$ & $\begin{array}{l}-0.110 \\
(0.370)\end{array}$ & $\begin{array}{l}-0.384 \\
(0.185)\end{array}$ \\
\hline Implied percent change & $-23.7 \%$ & $-7.7 \%$ & $-10.4 \%$ & $-31.9 \%$ \\
\hline Change per 100,000 drivers & -9.1 & -2.8 & -1.4 & -6.5 \\
\hline 4 th year drivers & $\begin{array}{c}-0.170 \\
(0.157)\end{array}$ & $\begin{array}{l}-0.009 \\
(0.252)\end{array}$ & $\begin{array}{c}0.056 \\
(0.491)\end{array}$ & $\begin{array}{l}-0.397 \\
(0.235)\end{array}$ \\
\hline Implied percent change & $-15.7 \%$ & $-0.9 \%$ & $5.8 \%$ & $-32.8 \%$ \\
\hline Change per 100,000 drivers & -4.3 & -0.2 & 0.4 & -4.8 \\
\hline \multicolumn{5}{|l|}{ Evening spillover: $8-10: 59 \mathrm{pm}$} \\
\hline 1st year drivers & $\begin{array}{c}-0.176 \\
(0.068)\end{array}$ & $\begin{array}{l}-0.275 \\
(0.122)\end{array}$ & $\begin{array}{l}-0.447 \\
(0.236)\end{array}$ & $\begin{array}{l}-0.116 \\
(0.089)\end{array}$ \\
\hline Implied percent change & $-16.2 \%$ & $-24.1 \%$ & $-36.0 \%$ & $-10.9 \%$ \\
\hline Change per 100,000 drivers & -31.7 & -43.8 & -16.8 & -11.4 \\
\hline 2nd year drivers & $\begin{array}{c}-0.051 \\
(0.106)\end{array}$ & $\begin{array}{l}-0.141 \\
(0.181)\end{array}$ & $\begin{array}{l}-0.010 \\
(0.322)\end{array}$ & $\begin{array}{c}0.044 \\
(0.146)\end{array}$ \\
\hline Implied percent change & $-5.0 \%$ & $-13.2 \%$ & $-1.0 \%$ & $4.5 \%$ \\
\hline Change per 100,000 drivers & -2.8 & -7.4 & -0.1 & 1.3 \\
\hline 3rd year drivers & $\begin{array}{c}-0.168 \\
(0.130)\end{array}$ & $\begin{array}{l}-0.006 \\
(0.226)\end{array}$ & $\begin{array}{c}0.041 \\
(0.399)\end{array}$ & $\begin{array}{c}-0.272 \\
(0.179)\end{array}$ \\
\hline Implied percent change & $-15.5 \%$ & $-0.6 \%$ & $4.2 \%$ & $-23.8 \%$ \\
\hline Change per 100,000 drivers & -5.8 & -0.2 & 0.3 & -5.1 \\
\hline 4 th year drivers & $\begin{array}{c}-0.318 \\
(0.163)\end{array}$ & $\begin{array}{l}-0.527 \\
(0.314)\end{array}$ & $\begin{array}{l}-0.469 \\
(0.515)\end{array}$ & $\begin{array}{l}-0.101 \\
(0.211)\end{array}$ \\
\hline Implied percent change & $-27.2 \%$ & $-40.9 \%$ & $-37.5 \%$ & $-9.6 \%$ \\
\hline Change per 100,000 drivers & -8.0 & -10.4 & -2.7 & -1.4 \\
\hline
\end{tabular}

Notes: This table shows the estimated effects for nighttime multi-passenger crash outcomes in the first four years of driving. The Poisson estimates come from equation (2) using driver-license and crash data from June 2004 to September 2014, and each regression uses 129,045,392 observations. The estimates in columns (1) and (2) for the 11:00pm-4:59am period are also presented in Figure 2. In this table, we also estimate the effect on the number of crashes where there is property damage but no casualties, which we include to value the effects of restriction. 
Table A9: The impact of the restriction on crashes for fully versus partially treated drivers

\begin{tabular}{cccc}
\hline & $\begin{array}{c}\text { Fully } \\
\text { treated } \\
(1)\end{array}$ & $\begin{array}{c}\text { Partially } \\
\text { treated } \\
(2)\end{array}$ & $\begin{array}{c}p \text {-value: } \\
(1)=(2)\end{array}$ \\
\hline 1st year drivers (under treatment) & -0.887 & -0.504 & 0.077 \\
& $(0.085)$ & $(0.213)$ & \\
Implied percent change & $-58.8 \%$ & $-39.6 \%$ & \\
Change per 100,000 drivers & -68.3 & -44.5 & \\
Drivers in $2^{\text {nd }}-4^{\text {th }}$ years & -0.409 & -0.183 & 0.069 \\
& $(0.079)$ & $(0.119)$ & \\
Implied percent change & $-33.6 \%$ & $-16.7 \%$ & \\
Change per 100,000 drivers & -47.5 & -26.1 & \\
\hline
\end{tabular}

Notes: This table presents the estimated changes in crash outcomes for drivers subject to the nighttime passenger restriction in their first full year of driving (fully treated) compared to drivers already in their first year when the restriction was introduced (partially treated). The Poisson estimates are based on a single regression from a version of equation (2) that allows for different effects for fully and partially treated drivers in each year of driving. The estimated effects on drivers in their $2^{\text {nd }}$ to $4^{\text {th }}$ years of driving are averaged to form one estimate based on the crash rates in each year of driving (and standard errors calculated using the delta method). The regression has 144,476,304 observations and is based on linked administrative driver-license and crash records from June 2004 to September 2014. The third column shows $p$-values from hypothesis tests that the reduction in crashes of fully treated drivers is the same as the reduction for partially treated drivers over a given period of driving experience. 


\section{B Predicting the most-responsible driver in multi-vehicle crashes}

For each crash in our data, the police make a judgment of the key vehicle causing the crash. These judgments are primarily based on the maneuvers of each vehicle prior to the crash (e.g., turning right, proceeding straight, stationary), which are included in our data. To minimize concerns that police judgments may change after the restriction was introduced (conditional on crash characteristics), we predict the most-responsible vehicle in all multi-vehicle crashes involving drivers in their first four years of driving who were carrying multiple passengers.

We use a logit Least Absolute Shrinkage and Selection Operator (LASSO) estimator to predict crash responsibility from pre-reform crashes. We allow the LASSO estimator to use several different types of variables to predict whether the reference vehicle (containing the firstto-fourth-year driver) is most responsible for the crash. We use variables measuring the:

(i) Maneuvers of the reference vehicle: dummy variables for stationary/parked; pulling out from a driveway; turning right or performing a U-turn (Australians drive on the left); turning left; proceeding straight in lane; waiting to turn; veering to change/merge lanes; driving on incorrect side of the road;

(ii) Maneuvers of other vehicles: we include the sum of the equivalent maneuver dummy variables in (i) for all other drivers involved in the crash, since some crashes involve more than two vehicles;

(iii) Type of impact: dummy variables for head-on crashes; rear-end crashes; right-angle crashes; other-angle crashes; vehicle-pedestrian crashes;

(iv) Characteristics of the reference driver: dummy variables for the different license types (Learner, P1, P2, Unrestricted); a dummy variable for whether the reference driver's vehicle was towed; dummy variables for whether the driver was speeding, fatigued, and had a blood alcohol concentration level above the limit; a male dummy variable; age in months; months of driving experience; dummy variables for whether the driver was killed and injured; and the number of people in the vehicle;

(v) Characteristics of all other drivers: we use the same characteristics as in (iv) and again sum across individual variables; 
(vi) Crash characteristics: dummy variables for the type of road (undivided two-way, divided road, dual freeway, T-intersection, other intersection); a dummy variable for being on local roads; dummy variables for the time period of the crash: daytime (8:00am-7:59pm), evening (8:00pm-10:59pm), nighttime (11:00pm-4:59am) or morning (5:00am-7:59am); dummy variables for whether the crash occurred in daylight or at dusk/dawn; dummy variables for crashes in Sydney and rural areas; dummy variables for the different speed limits of the road; the number of vehicles involved; the total number of people involved in the crash; a dummy variable for the crash being on a curved road; dummy variables for the crash involving at least one casualty and at least one serious casualty; and the sum of the age of all drivers involved in the crash.

Figure B1 shows the distribution of the fitted values from our LASSO model for pre-reform multi-vehicle crashes. Most of the mass is located close to probability 0 (not the most responsible driver) or probability 1 (the most responsible driver).

Figure B1: Histogram of predicted probabilities for the younger driver being most responsible for multi-vehicle crashes before the restriction was introduced

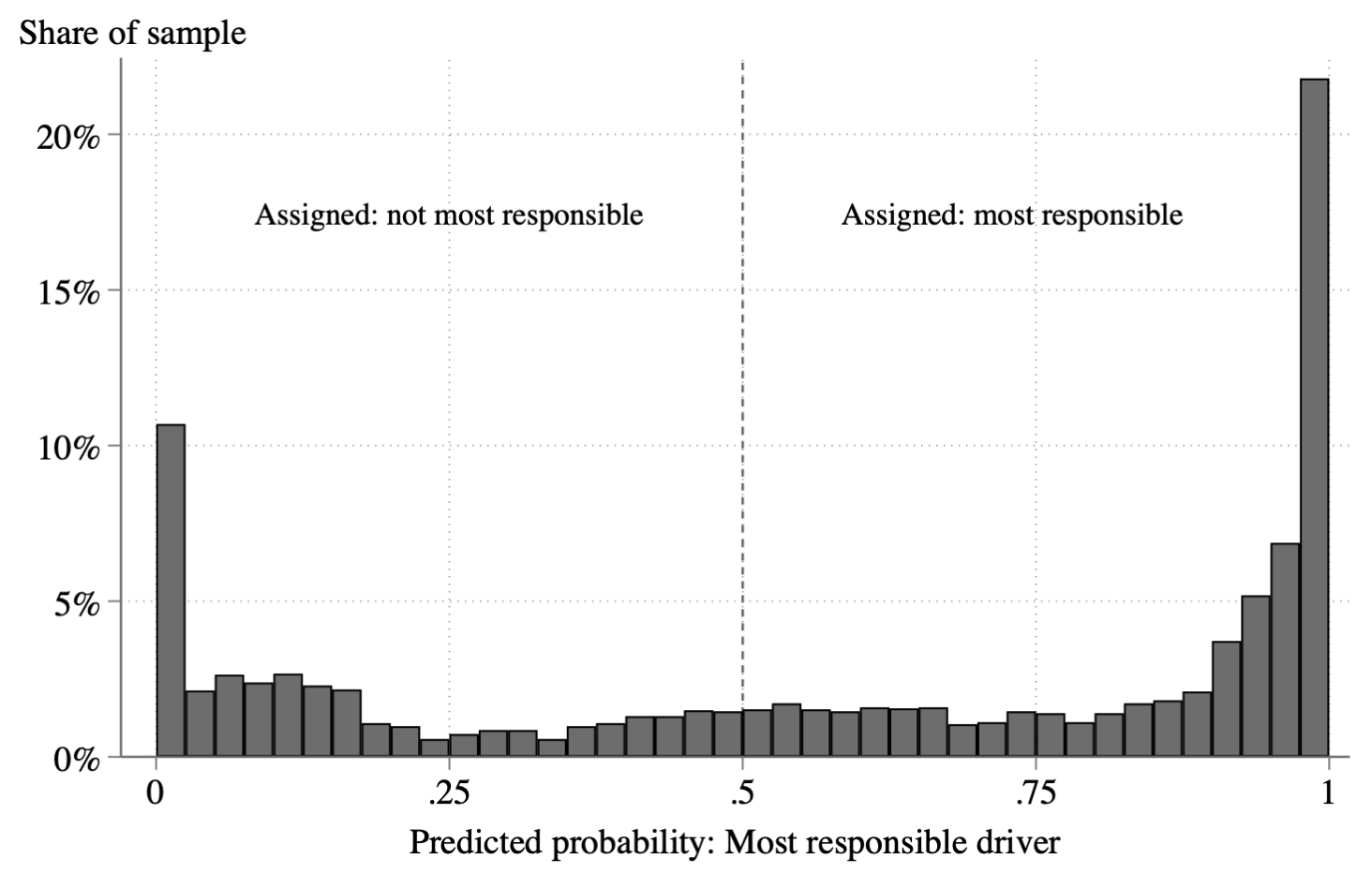


Based on an assignment rule where drivers with predicted probabilities greater than 0.5 are assigned to be the most responsible driver, our machine-learning model predicts that young drivers caused $61.8 \%$ of multi-vehicle crashes prior to the reform. This closely matches the $59.6 \%$ reported in police judgments. Moreover, the model correctly predicts the most responsible driver in $88.0 \%$ of crashes. Importantly, we find that the model predicts the most responsible driver with a similar level of accuracy after the reform (86.9\%), suggesting that we are not over-fitting the data. There is also a similarly high level of accuracy before and after the restriction if we focus on crashes during the restricted period ( $86.0 \%$ before and $86.4 \%$ after), which increases if we include data from single-vehicle crashes (92.7\% before and $94.0 \%$ after). This consistency minimizes concerns that police judgments may have changed once dealing with first-year drivers who were violating the nighttime passenger restriction.

Overall, given the high predictive power of our LASSO estimates of crash responsibility, it is no surprise that we find little difference in the estimates based on machine learning or police judgments. Figure 3 shows the estimates for the effects of the restriction on multi-vehicle crashes where the first-year driver was not responsible. Both measures produce similar estimates, which imply a slightly larger reduction in these types of crashes than all crashes.

Consistent with this, there is little change over time in the proportion of nighttime multipassenger crashes in which the young driver is most responsible. For the 11:00pm-4:59am period, Figure B2 shows the proportion of multi-passenger crashes caused by the driver in their first four years of driving for the three years before the restriction and seven years after. Using both police judgment and the machine-learning estimates, there is no evidence that the share of crashes caused by younger drivers changed after the restriction was introduced. We find a similar pattern if we restrict the sample to first-year drivers (not shown). Nighttime multi-passenger crashes not caused by younger drivers are declining in proportion to the decrease in all nighttime multi-passenger crashes. 
Figure B2: Share of multi-passenger crashes 11:00pm-4:59am caused by the younger driver

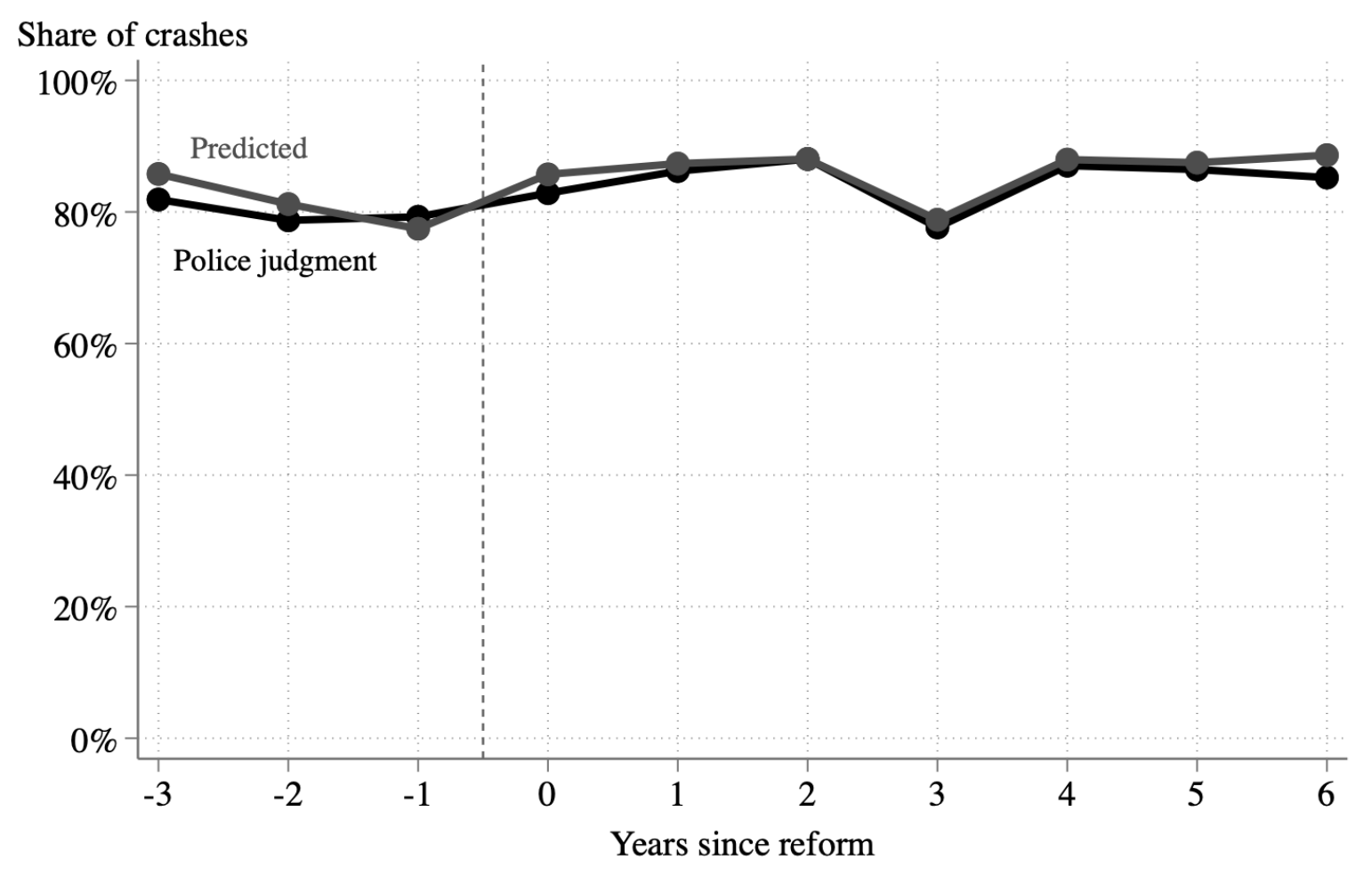




\section{Aggregating and valuing crash outcomes}

In this section, we provide more details about how we value the effects of the nighttime passenger restriction. All values are in 2019 Australian dollars, unless otherwise stated.

We use the values used by the NSW Government (Transport for NSW, 2019). Each traffic fatality is valued at $\$ 7.75$ million. For comparison, this is slightly lower than the value of statistical life estimate for Australia from Viscusi (2018) of $\$ 10$ million in 2015 dollars, or $\$ 10.9$ million in 2019 dollars once updated using Australian wage growth (Australian Bureau of Statistics, 2020). Other valuations are for serious injuries requiring hospitalization $(\$ 495,874$ each); minor injuries not requiring hospitalization $(\$ 77,472$ each); and crashes involving property damage but no injuries or fatalities $(\$ 10,338$ each).

We apply these values to the implied reductions from our estimates. For minor injuries and property-damage crashes, we use our estimates in Table A8 that come from equation (2). The number of minor injuries is equal to the change in casualties in column (2) minus the change in hospitalizations/deaths in column (3). For hospitalizations and fatalities, our first-year estimates come from using a single 8:00pm-4:59am treatment window and daytime outcomes from all crashes to increase precision (see Section 4). For the longer-term effects, we estimate a single treatment effect for the 8:00pm-4:59am period and use all drivers in their second-tofourth years of driving. This approach results in estimated reductions for every 100,000 first-year drivers of 0.9 fatalities and 7.1 hospitalizations, neither of which are statistically significant at conventional levels. We obtain similar estimates (0.6 fatalities and 7.4 hospitalizations) if we use the statistically significant effects on casualties in column (2) of Table A8 and assume that a constant fraction of casualties were hospitalizations and deaths throughout.

Overall, our estimates indicate that for every 100,000 first-year drivers subject to the restriction, there were changes of -163.7 crashes (-77.2 with casualties and -86.5 with just property damage), -97.8 minor injuries, -40.5 hospitalizations, and -5.9 deaths. With a $2 \%$ annual discount rate, these reductions are worth $\$ 412$ million in total or $\$ 738$ per driver subject to the restriction (valued in their first year of driving). This is our preferred estimate. If we only use statistically significant estimates and ignore the implied longer-term reductions in fatalities and hospitalizations, the value of the improvements decreases by $14 \%$. If we use the Viscusi (2018) estimate for the value of a statistical life in Australia, the value increases by $25 \%$. 